\title{
Experimental Investigation of Forchheimer Coefficients for Non-Darcy Flow in Conglomerate-Confined Aquifer
}

\author{
Tong Zhang, ${ }^{1,2}$ Yixin Zhao $\mathbb{D}^{1,3}$ Quan Gan, ${ }^{4}$ Liang Yuan, ${ }^{1,2}$ Guangpei Zhu, ${ }^{1,5}$ Yongbo Cai, ${ }^{1}$ \\ and Bao Cao ${ }^{1}$ \\ ${ }^{1}$ School of Resource and Safety Engineering, China University of Mining \& Technology, Beijing 100083, China \\ ${ }^{2}$ State Key Laboratory of Mining Response and Disaster Prevention and Control in Deep Coal Mines, Anhui University of Science \\ and Technology, Huainan, Anhui 232001, China \\ ${ }^{3}$ State Key Laboratory of Coal and Safe Mining, China University of Mining \& Technology, Beijing 100083, China \\ ${ }^{4}$ Department of Petroleum Geology \& Geology, School of Geosciences, University of Aberdeen, UK \\ ${ }^{5}$ College of Engineering Peking University, Beijing 100871, China
}

Correspondence should be addressed to Yixin Zhao; zhaoyx@cumtb.edu.cn

Received 8 May 2018; Revised 15 July 2018; Accepted 12 August 2018; Published 3 December 2018

Academic Editor: John A. Mavrogenes

Copyright ( 92018 Tong Zhang et al. This is an open access article distributed under the Creative Commons Attribution License, which permits unrestricted use, distribution, and reproduction in any medium, provided the original work is properly cited.

\begin{abstract}
A conglomerate-confined aquifer (CCA) plays an important role in affecting the safety and environmental protection during energy mining. In this study, the Forchheimer coefficients and associated seepage characteristics of the CCA were studied for different hydrogeological conditions via integrating theoretical analysis, hydromechanical experiment, and field investigation. Empirical models related to the intrinsic permeability $(k)$ and inertial resistance $(\beta)$ were developed based on theoretical and experimental solutions, governed by the parameters of particle size, initial porosity, and stress. The non-Darcy flow was obtained through experiments conducted with different ratios of the aggregate particle subjected to stress ranging from $1.43 \mathrm{MPa}$ to $4.38 \mathrm{MPa}$, and a discharge model associated with $k$ and $\beta$ was proposed. The aggregate particle and filling material of the CCA presented positive and negative effects on the interconnected pores, respectively, accompanied by wedging and wall effects. Distribution state of the aggregate particle and the filling material was affected by the stress, resulting in the reduction of the hydraulic conductivity and the weakening of the wedging and wall effects in the CCA. In addition, the transportation effect and broken effect occurred for the lower and higher stress situations and contributed to the shrinkage of the interconnected pores. Finally, the models of the CCA were validated using a normalized objective function (NOF), a linear slope $\gamma$ function, and field measurements.
\end{abstract}

\section{Introduction}

The seepage response widely exists in the study of gases, liquids, and geothermal activities [1-8]. The theories of Darcy flow and non-Darcy flow [9-13], which describe the relationship between the discharge and the hydraulic gradient, are widely used to investigate seepage behaviors in various fields, such as hydrocarbon resource mining of coal, coalbed methane, shale gas, tight sandstone gas [14-19], tunnel excavation, slope reinforcement, and underground mining [20-25], and also in the fields of garbage disposal, nuclear waste treatment, and sewage control [26]. Therefore, implications from investigating the seepage behavior and corresponding characteristics can greatly contribute to the development of geological science, energy mining, and the prevention and control of geological disasters.

Darcy's (1856) law has been widely applied in experiments and simulations, and it states that the discharge is proportional to the hydraulic gradient. However, this type of flow model is only appropriate for low velocity, steadiness, and laminar flow [27-31]. For a fluid seepage presented in high-velocity fluid and highly permeable porous media [32-35], the flow velocity and the hydraulic gradient do not have a linear relationship and was widely described by Forchheimer and Izbash laws [36, 37]. However, the stress effect for non-Darcy flows is seldom considered in the work efforts focused on fluid seepage in the porous media, such as unconsolidated porous media [38] and streambed packing 
[39]. It is widely accepted that geomechanical factors contribute significantly to the changes in the internal structure of porous media and the hydraulic conductivity. A conglomerateconfined aquifer (CCA) composed of conglomerate, coarse sandstone, and even uranium mine existed above the occurrence stratum of coal and oil plays an important role in the safety of coordinating mining of intergrown energy and resources and ecological protection; an example includes the area of the Ordos Basin [40, 41]. Therefore, by determining the Forchheimer coefficients and investigating corresponding seepage characteristics for CCA in various hydrogeological environments, this study contributes to the development of energy exploration and environmental protection.

The primary objective of this study is to determine the Forchheimer coefficients with the contribution of stress and investigate corresponding seepage characteristics for the CCA in various hydrogeological environments, including different components, hydraulic pressures, and stresses. Through theoretical derivation, a discharge model was proposed followed by the development of the models of $k$ and $\beta$. Subsequently, five groups of hydromechanical experiments were performed using porous media with different particle sizes and volume fractions and subjected to different stresses corresponding to various hydraulic gradients. The experimental results provided insights into the seepage behavior and the related characteristics. The optimized parameters for the $k$ and $\beta$ models were obtained through nonlinear regression, and a specific discharge model for the CCA was developed based on the experiments. Finally, comparisons between the predicted values, experimental values, and field measurement data were conducted to verify the accuracy of the proposed model.

The remainder of this paper is organized as follows: In Section 2, the theories of the flow regime are presented and the models of $k, \beta$, and the discharge are developed. In Section 3, the experimental preparation and procedures are described and the results are presented in Section 4. Finally, a discussion and a summary of the findings are presented in Sections 5 and 6, respectively.

\section{Establishment of the Theoretical Model}

For the fluid flow in porous media with complex structure, various flow regimes such as Darcy flow, weak inertial flow, non-Darcy flow, and turbulent flow can be identified. We focus on Forchheimer's law to investigate the seepage behavior of the CCA because it can well describe the linear and nonlinear fluid flow. Moreover, the specific formation of Forchheimer's law is presented as follows:

$$
-J=A v+B v^{2}
$$

where $J\left[\mathrm{ML}^{-2} \mathrm{~T}^{-2}\right]$ represents the hydraulic gradient, $v$ $\left[\mathrm{LT}^{-1}\right]$ is the flow velocity, $A\left[\mathrm{ML}^{-3} \mathrm{~T}^{-1}\right]$ is the non-Darcy coefficient given by $\mu / k$ with $k\left[\mathrm{~L}^{2}\right]$ defined as the intrinsic permeability and $\mu\left[\mathrm{ML}^{-1} \mathrm{~T}^{-1}\right]$ as the dynamic viscosity, and $B\left[\mathrm{ML}^{-4}\right]$ is the coefficient expressed by $\beta \rho$ with $\beta\left[\mathrm{L}^{-1}\right]$ and $\rho\left[\mathrm{MT}^{-3}\right]$ as the non-Darcy coefficient and the density of the fluid, respectively. The two terms on the right-hand side of (1) represent the viscous and inertial energy loss mechanisms, respectively.

It is evident that the coefficient $A$ in (1) depends on the effective stress based on the relationship between $k$ and the stress described by the power function providing a reasonable description of the permeability-stress relationship for relatively low stress [42-44] in Darcy's law:

$$
k=a \sigma^{-b}
$$

where $\sigma\left[\mathrm{ML}^{-1} \mathrm{~T}^{-2}\right]$ is the effective stress, $k\left[\mathrm{~L}^{2}\right]$ is the intrinsic permeability corresponding to $\sigma$, and $a$ and $b$ are material constants.

2.1. The Forchheimer Coefficients $A$ and B. For the purpose of using Forchheimer's law in the field of analytical or numerical solutions, the determination of the Forchheimer coefficients $A$ and $B$ in (1) is necessary. Considerable research efforts have been devoted to determining the coefficients $A$ and $B$ for different particle sizes and porosities of porous media [45-48]. The coefficients $A$ and $B$ in Forchheimer's law were estimated by Ergun [49] who proposed modified functions based on the classical Kozeny-Carman model that incorporates the particle diameter and porosity of porous media as follows:

$$
\begin{aligned}
& A=\frac{150 \mu(1-n)^{2}}{n^{3} d^{2}}, \\
& B=\frac{1.75(1-n) \rho}{n^{3} d},
\end{aligned}
$$

where $n$ is the porosity of the porous media and $d[\mathrm{~L}]$ is the diameter of the porous media. Subsequently, similar expressions were developed by $[50,51]$, all of whom took the effect of porosity into account.

2.2. The Correlation between $\beta$ and the Stress. Considering the effect of the effective stress on the porosity, an exponential relationship between porosity and stress was developed based on numerous studies [52-54]:

$$
n=n_{0} \exp (-\tau \sigma)
$$

where $\tau$ is the stress sensitivity coefficient and $n_{0}$ is the initial porosity of the porous media. In subsequent studies, Huang et al. [55] developed a model for formulating $\beta$ as a function of porosity:

$$
\beta=h n^{-\xi}
$$

where $h$ and $\zeta$ are the material and exponent coefficients, respectively. Based on the above-mentioned research efforts, by combining the exponential relationship shown in (7) and (8) and eliminating the porosity $n$, it is evident that $\beta$ can be expressed by stress in the form of an exponential equation:

$$
\beta=\eta \exp (c \sigma)
$$


where $\eta$ is the attribute parameter of the porous media and $c$ is the stress sensitivity parameter.

2.3. Empirical Models of $k, \beta$, and Discharge. Combining (1), $(3 a)$, and $(3 b)$, after unifying the dimensional units, we find that $k$ and $\beta$ depend on the particle diameter and the porosity. Consequently, by combining the results with (1), (2), (3a), (3b), and (6), the models of $k$ and $\beta$ can be obtained as follows:

$$
\begin{aligned}
& k=f(\sigma) f(n) f(D)=a_{0} \frac{n^{\zeta_{2}}}{(1-n)^{\zeta_{3}}}(D)^{\zeta_{1}}(\sigma)^{-m}, \\
& \beta=f(\sigma) f(n) f(D)=b_{0} \exp (c \sigma) \frac{(1-n)^{\zeta_{5}}}{n \zeta_{6}}(D)^{-\zeta_{4}},
\end{aligned}
$$

where $D[\mathrm{~L}]$ is the diameter of the aggregate particle; $a_{0}$ and $b_{0}$ are the initial attribute parameters representing the effects of the shape of the pores and particles, pore throat, and tortuosity on the porous media; $\zeta_{1}$ and $\zeta_{4}$ are the particle diameter coefficients; $\zeta_{2}, \zeta_{3}, \zeta_{5}$, and $\zeta_{6}$ are the porosity coefficients; and $m$ is the stress parameter. Notably, the porosity $n$ is also affected by stress; however, due to the nonunique expressions for distinct materials and conditions $[44,53,54]$, a specific correlation should be obtained through relevant experiments. For simplicity, hereafter, we just use the final porosity $n$ calculated by the porosity-stress law, such as (4), into consideration for a reanalysis of the experimental data.

Furthermore, a discharge model of the fluid flow is proposed based on a previous study [56] using the $k$ model $((7))$ and the $\beta$ model $((8))$.

$$
\begin{aligned}
& v=\frac{2|-J|}{A+\sqrt{A^{2}+4 B|-J|}}, \\
& A=\frac{\mu}{k}=a \mu \frac{(1-n)^{\zeta_{3}}}{n^{\zeta_{2}}}\left(\frac{1}{D}\right)^{\zeta_{1}}(\sigma)^{-m}, \\
& B=\beta \rho=b_{0} \rho \exp (c \sigma) \frac{(1-n)^{\zeta_{5}}}{n_{6}}(D)^{-\zeta_{4}} .
\end{aligned}
$$

2.4. The Criteria of Linear and Nonlinear Flow. Because the determination of the transition from linear flow to nonlinear flow is critical for porous media, a large number of studies have been conducted on this subject [57]. Normally, the Reynolds number Re and the Forchheimer number $F_{0}$ have been widely used to describe the transition point [58]; the Re expression is defined as

$$
\mathrm{Re}=\frac{\rho \theta v}{\mu}
$$

where $\theta[\mathrm{L}]$ is the characteristic length of the porous media, $\mu\left[\mathrm{ML}^{-1} \mathrm{~T}^{-1}\right]$ is the dynamic viscosity, and $v\left[\mathrm{LT}^{-1}\right]$ is the flow velocity. Ma and Ruth [59] defined the criterion of
TABLE 1: Experimental materials of conglomerate-confined aquifer.

\begin{tabular}{lcccc}
\hline Strata & \multicolumn{4}{c}{ Conglomerate confined aquifer } \\
Material & $\begin{array}{c}\text { Sandstone } \\
\text { (small) }\end{array}$ & $\begin{array}{c}\text { Cobble } \\
\text { (middle) }\end{array}$ & $\begin{array}{l}\text { Cobble } \\
\text { (large) }\end{array}$ & $\begin{array}{c}\text { Fine } \\
\text { sand }\end{array}$ \\
\hline Diameter $[\mathrm{mm}]$ & $10 \sim 20$ & $20 \sim 30$ & $30 \sim 50$ & $0.5 \sim 2$ \\
Density $\left[\mathrm{kg} / \mathrm{m}^{3}\right]$ & 2580.4 & 2744.7 & 2531.9 & 2090.4 \\
\hline
\end{tabular}

the Forchheimer number, $F_{0}$, as the ratio of the inertial to the viscous losses:

$$
F_{0}=\frac{k \beta \rho v}{\mu} .
$$

Compared with the Reynolds number, the Forchheimer number possesses the advantage of a clear definition, an explicit physical meaning, and wide applicability in engineering.

The non-Darcy effect $E$ is the ratio of the hydraulic gradient induced by the inertial forces to the total hydraulic gradient, and it is defined as

$$
E=\frac{\beta \rho v^{2}}{-J} .
$$

Substituting (1) and (14) into (16), $E$ is formulated as a function of the Forchheimer number:

$$
E=\frac{F_{0}}{1+F_{0}} .
$$

A large number of critical values of $F_{0}$ have been evaluated for porous media; Zeng and Grigg [36] suggested $E=10 \%$ as a threshold for the nonlinear fluid flow effect, which corresponds to a critical $F_{0}$ of 0.11 . Using a graphical evaluation of laboratory column experiments, Ghane et al. [26] estimated a high average critical value $F_{0}$ of 0.31 . An even higher average critical value of 0.40 corresponding to $E=28 \%$ for nonlinear fluid flow was discovered by Macini et al. [38] for natural sand.

\section{Experimental Preparation and Procedure}

3.1. Material Preparation. The CCA in the Ordos Basin is characterized by a mixture of coarse sandstone and fine sand in a loose state. The experimental materials are composed by sandstone (small), cobblestone (medium), and cobblestone (large) with ranges of diameter $10 \sim 20 \mathrm{~mm}, 20 \sim 30 \mathrm{~mm}$, and $30 \sim 50 \mathrm{~mm}$ with corresponding densities of $2531.9 \mathrm{~kg} / \mathrm{m}^{3}$, $2744.7 \mathrm{~kg} / \mathrm{m}^{3}$, and $2580.4 \mathrm{~kg} / \mathrm{m}^{3}$ as aggregates and fine sand with a density of $2090.4 \mathrm{~kg} / \mathrm{m}^{3}$ as the filling material. During the experiment, different aggregates were mixed together at specific ratios. In addition, different quantities of fine sand were added to each group; the specific details of the mixture are shown in Table 1 and Figure 1.

3.2. Experimental Procedure. The fluid seepage of the CCA was investigated using a test system consisting of mixed porous media packed in a cylinder with dimensions of $400 \mathrm{~mm} \times 680 \mathrm{~mm}$ (diameter $\times$ height $)$ with different axial 


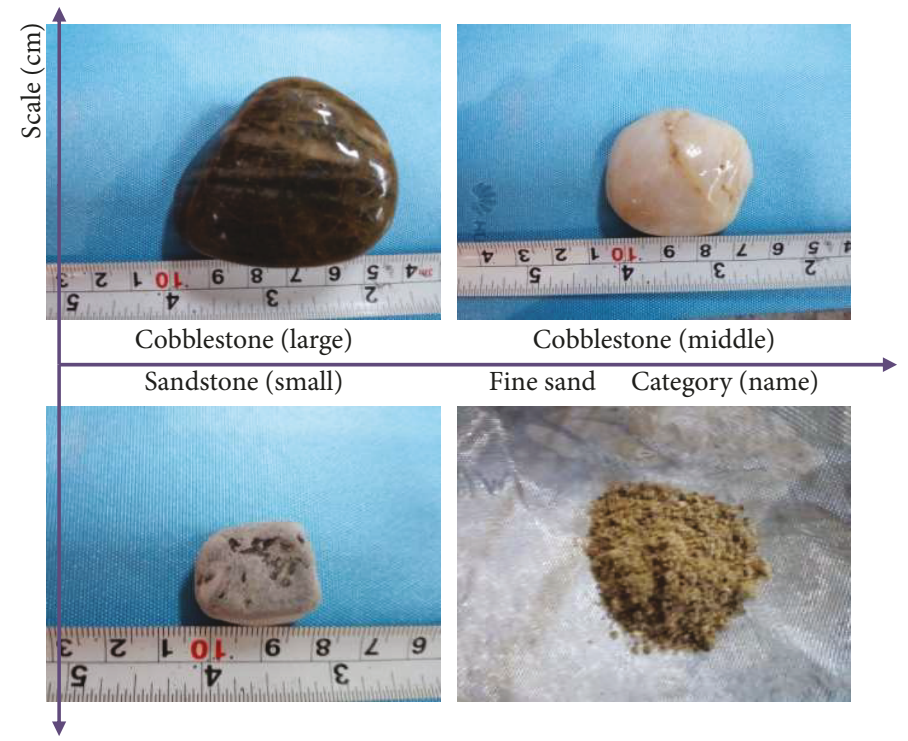

Figure 1: Detail of experimental media.

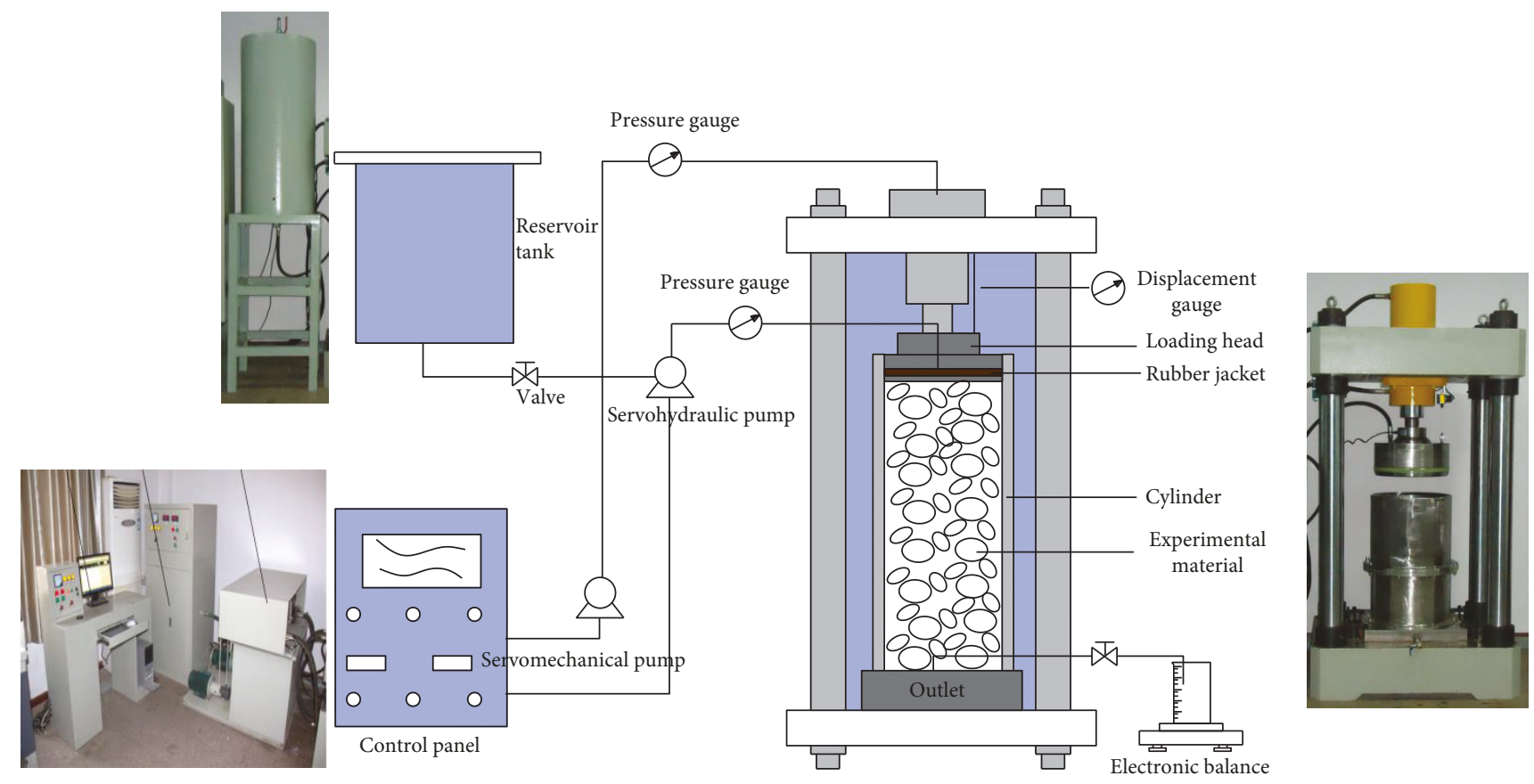

FIgURE 2: Schematic diagram of the experimental system.

loads subjected to various hydraulic gradients at a temperature of $10^{\circ} \mathrm{C}$, as shown in Figure 2 . Following the preparation of the experimental materials, the loading head was pushed down to the surface of the mixture along the axial direction under the control of servomechanical pumps, applying a maximum stroke of $400 \mathrm{~mm}$ and a precision of $0.01 \mathrm{~mm}$ associated with a maximum axial load of $600 \mathrm{kN}$ and a resolution of $0.01 \mathrm{kN}$. The performance of the servohydraulic pumps had a resolution of $0.15 \mathrm{~L} / \mathrm{h}$, providing a relatively wide range in the hydraulic gradient from $0 \mathrm{MPa}$ to $4 \mathrm{MPa}$ and corresponding to a minimum time interval of 10 times/s. The experiments were conducted under various hydraulic gradients, and the discharge rate was accurately recorded at the outlet by an electronic balance.

In order to study the seepage behavior of the CCA with influence factors including porosity and particle size under the effect of stress for various hydraulic gradients, the experimental mixture was divided into two categories composed of three groups each, as shown in Table 2. For each group, five different stress paths were investigated and at each axial stress, nine to thirteen sets of hydraulic test were conducted 
TABLE 2: The ratio condition of experimental material.

\begin{tabular}{lccccc}
\hline Category & $\begin{array}{c}\text { Sandstone } \\
(\text { small }) \\
{[\mathrm{kg}]}\end{array}$ & $\begin{array}{c}\text { Cobble } \\
(\text { middle }) \\
{[\mathrm{kg}]}\end{array}$ & $\begin{array}{c}\text { Cobble } \\
(\text { large }) \\
{[\mathrm{kg}]}\end{array}$ & $\begin{array}{c}\text { Fine } \\
\text { sand } \\
{[\mathrm{kg}]}\end{array}$ & $\begin{array}{c}\text { Ratio of } \\
\text { aggregate }\end{array}$ \\
\hline Group 1 & 40 & 40 & 40 & 17.74 & $1: 1: 1$ \\
Group 2 & 24 & 48 & 48 & 17.74 & $1: 2: 2$ \\
Group 3 & 17 & 52 & 52 & 17.74 & $1: 3: 3$ \\
Group 4 & 13.4 & 53.3 & 53.3 & 17.74 & $1: 4: 4$ \\
Group 4-1 & 13.4 & 53.3 & 53.3 & 24 & $1: 4: 4$ \\
Group 5 & 13.4 & 53.3 & 53.3 & 30 & $1: 4: 4$ \\
Group 6 & 13.4 & 53.3 & 53.3 & 36 & $1: 4: 4$ \\
\hline
\end{tabular}

using a hydraulic gradient in the range of $0 \mathrm{MPa}$ to $1.8 \mathrm{MPa}$. The experimental steps were as follows:

(1) An axial stress load of $100 \mathrm{kN}$ was applied at a rate of $20 \%$ with manual loading, ensuring that the loading head fully contacted the surface of the experimental mixture. Subsequently, a loading of $180 \mathrm{kN}$ was applied automatically at the speed of $0.2 \mathrm{kN} / \mathrm{s}$ and maintained at a given level for approximately $1.5 \mathrm{~h}$.

(2) The hydraulic pressure load was subsequently increased to $0 \mathrm{MPa}, 0.025 \mathrm{MPa}, 0.05 \mathrm{MPa}, 0.1 \mathrm{MPa}$, $0.2 \mathrm{MPa}, \quad 0.4 \mathrm{MPa}, \quad 0.6 \mathrm{MPa}, \quad 0.8 \mathrm{MPa}, \quad 1.0 \mathrm{MPa}$, 1.2 MPa, 1.4 MPa, 1.6 MPa, and 1.8 MPa. The fluid discharge was measured by the flow method corresponding to the different hydraulic pressures.

(3) The axial stress load was increased automatically to $350 \mathrm{kN}, 450 \mathrm{kN}, 500 \mathrm{kN}$, and $550 \mathrm{kN}$ with a speed of $0.2 \mathrm{kN} / \mathrm{S}$, followed by a repeat of step (2) in each stress state. Each magnitude of axial stress state was maintained for about $1.5 \mathrm{~h}$. Notably, in order to diminish the impact of the coupled hydraulicmechanical (HM) gradient on the flow regime in a certain period, the hydraulic gradient was released prior to the axial compression and the displacement of the radial direction was fixed based on the analysis provided by Chen et al. [60].

3.3. Porosity Measurement. The height $h_{\mathrm{s}}$ of the experimental media were recorded without the stress effect and the initial porosity was described as follows:

$v_{\varphi}=\frac{h_{\mathrm{s}} \pi d^{* 2}}{4}-\left(\frac{m_{1}}{\rho_{1}}+\frac{m_{2}}{\rho_{2}}+\ldots .+\frac{m_{n}}{\rho_{n}}\right)$,

$n_{0}=\frac{4 v_{\varphi}}{h_{s} \pi d^{* 2}}=1-\frac{4}{h_{s} \pi d^{* 2}}\left(\frac{m_{1}}{\rho_{1}}+\frac{m_{2}}{\rho_{2}}+\ldots .+\frac{m_{n}}{\rho_{n}}\right)$,

where $d^{*}[\mathrm{~L}]$ is the diameter of the cylinder, $v_{\varphi}\left[\mathrm{L}^{3}\right]$ is the volume of the pore, $\rho_{1}, \rho_{2} \ldots, \rho_{n}\left[\mathrm{ML}^{-3}\right]$ are the densities of the different materials, and $m_{1}, m_{2} \ldots, m_{n}[\mathrm{M}]$ are the corresponding material qualities.

The dynamic porosity was described by the ratio of the dynamic void to the dynamic volume of the porous media caused by the displacement of the loading head recorded by a displacement sensor placed at the loading head. By eliminating the cross-sectional area $\pi d^{2}$, the final expression of porosity can be calculated as follows:

$$
\begin{aligned}
& v_{\varphi t}=\frac{\left(h_{s}-h_{t}\right) \pi d^{2}}{4}-\left(\frac{m_{1}}{\rho_{1}}+\frac{m_{2}}{\rho_{2}}+\ldots .+\frac{m_{n}}{\rho_{n}}\right), \\
& n=\frac{4 v_{\varphi t}}{\left(h_{s}-h_{t}\right) \pi d^{2}}=1-\frac{4}{\left(h_{s}-h_{t}\right) \pi d^{2}}\left(\frac{m_{1}}{\rho_{1}}+\frac{m_{2}}{\rho_{2}}+\ldots+\frac{m_{n}}{\rho_{n}}\right),
\end{aligned}
$$

where $h_{t}[\mathrm{~L}]$ denotes the displacement of the loading head.

\section{Results and Analysis}

According to the experiments, 385 data points were collected as the average value of three tests per point and were displayed as the hydraulic gradient $(-J)$ versus the discharge $(v)$ and the axial stress versus the porosity; the details are shown in Appendix A (Supplementary Material doc available here). The data were analyzed using a quadratic polynomial regression based on Forchheimer's law ((1)) and considering the gravity effect [61] because the data were measured at the lower outlet affected by gravity. It is worth mentioning that the coefficients of $k$ and $\beta$ are taken into account in the following analysis and the relevant dynamic viscosity $1.308 \times 10^{-3} \mathrm{~Pa} \cdot \mathrm{s}$ (corresponding to a temperature of $10^{\circ} \mathrm{C}$ ) and density $1.0 \times 10^{3} \mathrm{~kg} / \mathrm{m}^{3}$ of water were assumed in the calculations.

4.1. Characterization of the Flow Regime and Correlations between Key Parameters. Although the investigated material consisted of cobblestone and sandstone with different particle sizes and fine sand (Figure 3), the following representative results of group four under various axial stresses corresponding to different hydraulic gradients indicated that Forchheimer's law adequately described the seepage behavior in the CCA.

The hydraulic losses of the fluid are primarily attributed to the viscous and inertial effects that can be determined using (1). The inertial losses that mainly depend on a complex structure and fluid velocity significantly affect the seepage behavior of the CCA. As a result, the seepage characteristics of the CCA are greatly related to the properties of the porous media, such as porosity, pore shape, tortuosity, and fluid velocity, and also involve the interaction between the fluid and the porous media characterized by dynamic viscosity $[47,49,51]$. The Forchheimer number $F_{0}$ and the nonDarcy effect $E$ were used as the criteria for determining the flow regime in this analysis. The results of applying (13) and (15) are shown in Figure 3, which indicates that the value of $F_{0}$ increased from 0.247 to 3.88 , corresponding to changes in $E$ ranging from 0.198 to 0.795 . The results imply that the internal structure experienced significant changes induced by the initial distribution of the material's components and the postperiod stress effect. Simultaneously, the hydromechanical experiments being conducted in non-Darcy flow were confirmed by considering the non-Darcy flow criterion documented by [36], who recommended a Forchheimer 

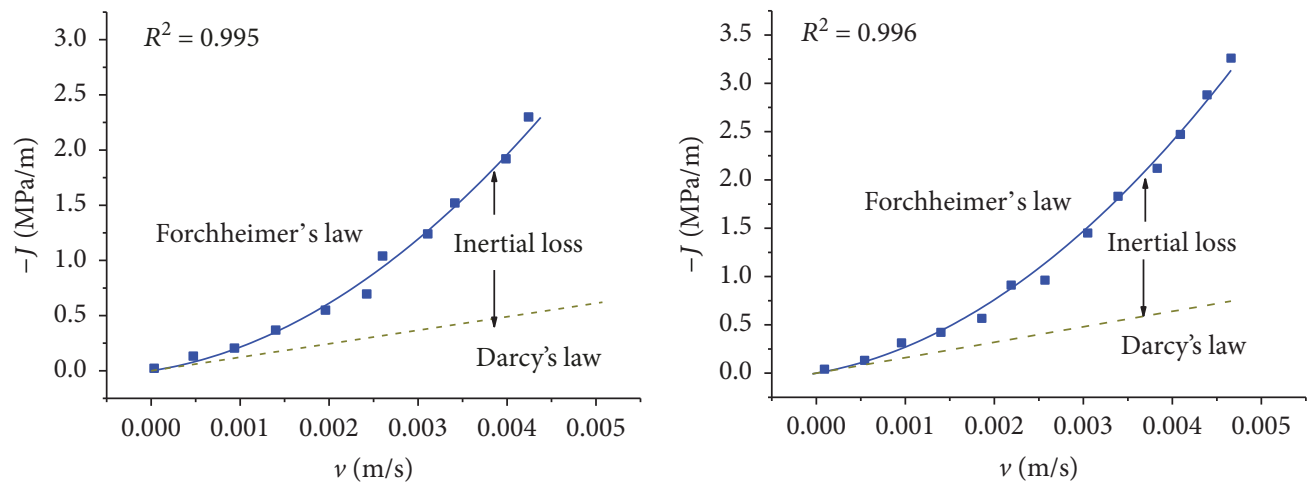

- Exp data 1.43MPa

$-J=1.2 \mathrm{E} 8 v+9.18 v^{2}$

$-J=1.2 \mathrm{E} 8 v$

(a)

- Exp data 2.79MPa

$-J=1.6 \mathrm{E} 8 v+1.1 \mathrm{E} 11 v^{2}$

$\cdots-J=1.6 \mathrm{E} 8 v$

(b)
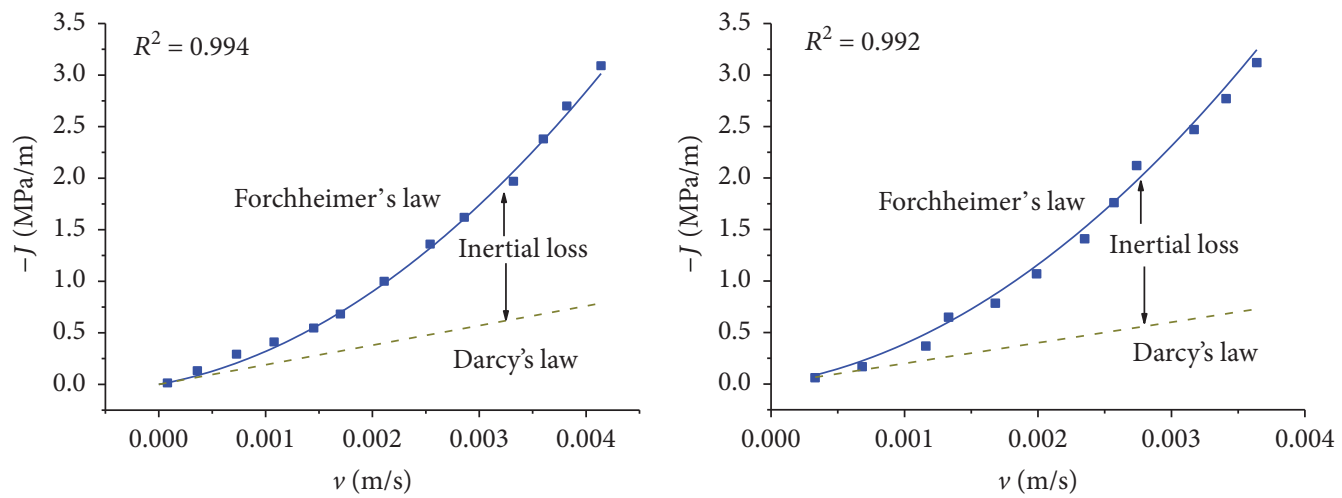

- Exp data 3.58MPa

$-J=1.9 \mathrm{E} 8 v+1.3 \mathrm{E} 11 v^{2}$

$-J=1.9 \mathrm{E} 8 v$

- Exp data 3.98MPa

$-J=2 \mathrm{E} 8 v+1.9 \mathrm{E} 11 v^{2}$

$-J=2 \mathrm{E} 8 v$

(c)

(d)

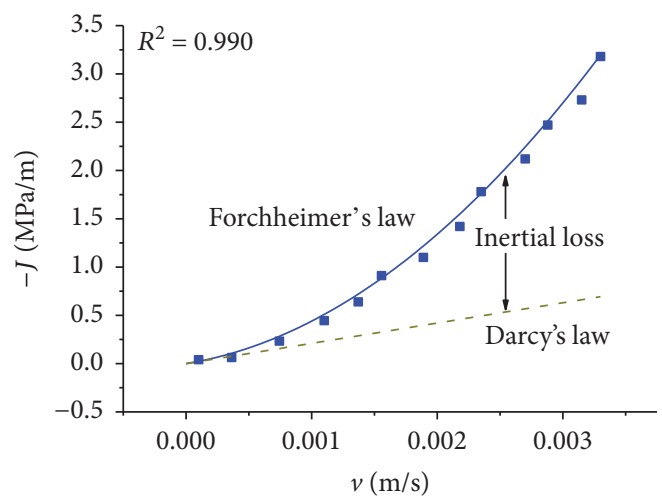

- Exp data 4.38MPa

$-J=2.1 \mathrm{E} 8 v+2.3 \mathrm{E} 11 v^{2}$

$-J=2.1 \mathrm{E} 8 v$

(e)

Figure 3: Characteristic of flow regime under different stresses.

number and suggested a critical $F_{0}$ of 0.11 as the threshold to determine the non-Darcy flow.

Using $100 \mathrm{kN}$ as a starting point, a nonlinear regression function of the exponential law was used to analyze the influence of the stress on the porosity; a good fit was confirmed with a determination coefficient $R^{2}=0.982$ (Figure 4). The regression results are in good agreement with studies on Darcy flow. The porosity decreased with an 


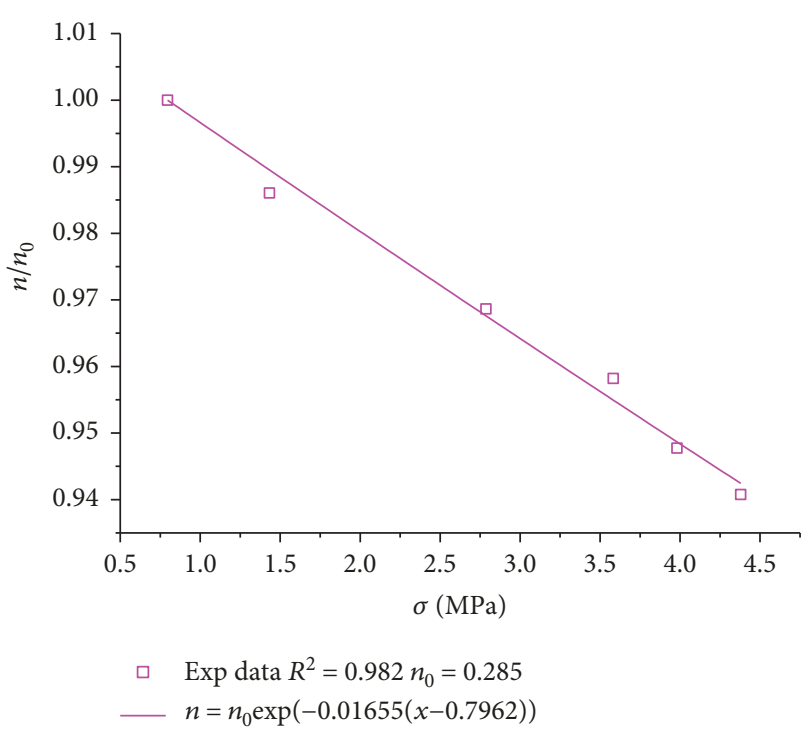

FIGURE 4: Power function relationship between porosity and stress.

increase in the stress; specifically, the decrease was in the range of 0.283 to 0.270 as the axial stress increased from 1.43 MPa to $4.38 \mathrm{MPa}$. It is evident that the porosity changed due to the shrinking of the voids formed by the aggregate particle and the movement of fine sand induced by the stress, which provided the opportunity to study the effect of stress on the characteristics of fluid seepage in the CCA.

Based on the experimental results, (2) is adequate for describing the correlation of stress permeability for the CCA with the parameters values for $a$ and $b$ of $1.311 E-11$ and 0.49604 , respectively. A high determination coefficient $R^{2}=0.99$ was obtained for the stress in the range of 1.43 MPa 4.38 MPa (Figure 5(a)). In addition, Figure 5(a) also indicates that the internal structure changed markedly under the effect of the stress, resulting in a decrease in $k$ from $1.09 E-11 \mathrm{~m}^{2}$ to $6.884 E-12 \mathrm{~m}^{2}$ for the relatively small stress ranging from $1.43 \mathrm{MPa}$ to $4.38 \mathrm{MPa}$. In contrast, the value of $k$ varied in a relatively narrow range of $6.284 E-12 \mathrm{~m}^{2} \sim 6.2286 E-12 \mathrm{~m}^{2}$ in a relatively high stress range of $3.58 \mathrm{MPa}$ to $4.38 \mathrm{MPa}$; this illustrates that the internal structure exhibits less sensitivity to the changes in the stress as the density increases. Simultaneously, the stress ranged from 1.43 $\mathrm{MPa}$ to $3.58 \mathrm{MPa}$, indicating that the reduction in permeability was primarily subjected to a normal compaction response.

Figure 5(b) shows that $\beta$ is positively correlated with an increase in the stress, according to (9). Hence, by using (6), an improved nonlinear regression was developed for the experimental data and the coefficients were $\eta=3.98 \mathrm{e} 7$, $c=0.387$. Specifically, as the stress increased from $1.43 \mathrm{MPa}$ to $4.38 \mathrm{MPa}$, the corresponding $\beta$ increased from $9.18 \mathrm{E} 10 \mathrm{~m}^{-1}$ to $2.3 \mathrm{E} 11 \mathrm{~m}^{-1}$. During this process, $\beta$ exhibited sensitivity to the increase in the stress from $3.58 \mathrm{MPa}$ to $4.38 \mathrm{MPa}$, a result that is consistent with the performance of $\beta=1.9 \times 10^{-8} \mathrm{gk}-1.8$ and $\beta=k^{-0.5} n^{-5.5}$ documented in the references of $[26,62]$. This indicates that $k$ and $\beta$ are characterized by opposite responses to changes in the internal structure as a result of the change in stress.
4.2. The Effect of Initial Porosity. The media used in this study are different from conventional porous media because of different particle sizes and volume fractions of the components determined by the geomechanics and the hydrogeological conditions of the CCA. Consequently, the influence of the particle size and the initial porosity on the Forchheimer coefficients $k$ and $\beta$ may differ from previous experiments [48-50]. Nevertheless, the CCA is within the scope of porous media.

The aggregate particle remained almost intact for the whole experiment, which indicates that the destruction of the internal structure was mainly induced by the space compaction, caused by the movements of the large particles and fine sand. Eventually, this compaction process will result in the changes of $k$ and $\beta$. The first category (group 4, group $4-1$, group 5 , and group 6) of data contained the same ratio of aggregate particle, and different quantities of fine sand were selected to study the influence of the initial porosity on the values of $k$ and $\beta$ subjected to various stresses, eliminating the effect of particle size. The results are shown in Figures 6 and 7.

For each of the stress states (shown in Figure 6), $k$ continuously increased with an increase in the porosity and was characterized by a downward concave shape; this indicates that $k$ increased smoothly for a lower porosity, while a greater increase was obtained for higher porosity in all cases. The maximum value of $0.833 E-11 \mathrm{~m}^{2}$ was observed in group 4 under a stress of $1.43 \mathrm{MPa}$ and a porosity of 0.283 , whereas the minimum value of $0.102 E-11 \mathrm{~m}^{2}$ occurred in group 6 corresponding to a stress of $4.38 \mathrm{MPa}$ and a porosity of 0.182 . In addition, except for porosity, $k$ was also negatively correlated to the stress, which was in agreement with the results for group 4. Using a nonlinear regression and considering the effect of stress, we conclude that the relationship between stress, porosity, and $k$ can be adequately described by the following equation:

$$
k=a_{1} \sigma^{-m} \frac{n^{\zeta_{3}}}{(1-n)^{\zeta_{2}}}
$$

where $n$ is the initial porosity of the experiment media under a certain stress state, $\zeta_{2}$ and $\zeta_{3}$ are the regression parameters of 2 and 4.5, respectively, $m$ is the stress parameter in the range of $1.08 \sim 1.18$, and $a_{1}$ is a property parameter ranging from 0.035 to 0.190 .

It is evident from Figure 7 that, in contrast to the positive relationship between $k$ and porosity, $\beta$ exhibited a negative correlation with porosity under different stress conditions represented by a dynamic declining trend for low porosity compared to a smooth variability for high porosity; the change was characterized by a downsloping concave curve. For a stress of $4.38 \mathrm{MPa}$ and a porosity of 0.182 in group $6, \beta$ reached a maximum value of $13 \mathrm{E} 8 \mathrm{~m}^{-1}$. The minimum value of $\beta$ was $0.918 \mathrm{E} 8 \mathrm{~m}^{-1}$, which occurred in group 4 with a stress of $1.43 \mathrm{MPa}$ and a porosity of 0.283 . Simultaneously, $\beta$ was positively related to the stress in group 4 , group 5 , and group 6 . We conclude that 


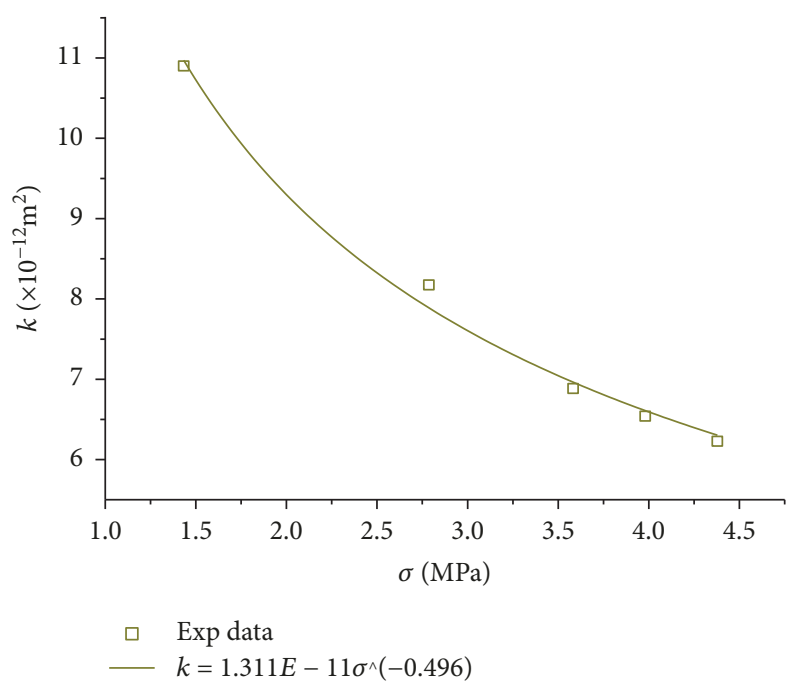

(a)

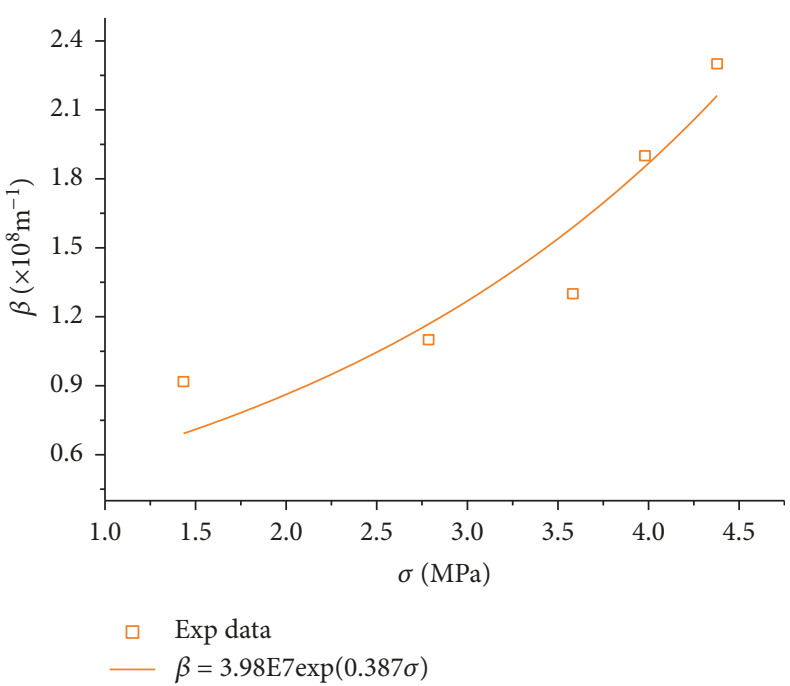

(b)

FIGURE 5: Relation between relative parameters: (a) the relation between permeability and stress and (b) the relation between $\beta$ and stress.

(20) can accurately describe the changes in $\beta$ associated with changes in stress and porosity:

$$
\beta=\frac{b_{1} \exp (c \sigma)(1-n)^{\zeta 5}}{n^{\zeta}},
$$

where $\zeta_{5}$ and $\zeta_{6}$ are the regression parameters of 2 and 4 , respectively, $c$ is the stress parameter ranging from $2.16 E-6$ to $2.297 E-6$, and $b_{1}$ is the attribute coefficient in a range from 229.1 to 243.6 . Notably, it is evident that, when $\sigma$ equals 0 , the value for $\beta((3 \mathrm{~b}))$ is consistent with non-Darcy flow work without stress effect [49-51].

The experimental results for the coefficients $k$ and $\beta$ indicate that the quantity of fine sand distributed in the conglomerate mainly determines the initial porosity of the CCA with a constant value for the aggregate grain; this is in agreement with the research results of $[63,64]$, who pointed out that the porosity increased with a decrease in the small particle fraction beyond the minimum porosity point. As the amount of fine sand is reduced, fewer small particles are involved in the wall effect [65] and the wedging effect [63], resulting in the increase in the dead volume (zones free of small particles) close to the contact points of the large particles and the voids formed by the large particles. Finally, these effects result in the increase in the porosity of the experimental mixture and the increased porosity results in high hydraulic conductivity. In addition, due to the decrease in the number of small particles, the wall effect near the surface of the large particles creates more pore channels, resulting in the increase in the liquid fraction due to a lower density or voids near the surface; therefore, the flow pathways are shortened. Simultaneously, the speed in the growth of the conductivity channels and the shortening of the flow pathways are nonlinearly correlated with the increased porosity, resulting in the nonlinear changes in $k$ and $\beta$. In summary, the reduction in the fine sand provides a good opportunity for flow through the mixture characterized by a reduction in the viscosity and internal force represented by the increase in $k$ and the decrease in $\beta$.

4.3. The Role of Particle Size of the CCA. To evaluate the effect of the particle size on the changes in $k$ and $\beta$, group 1, group 2 , group 3, and group 4 were prepared, in which the ratios of the components are $1: 1: 1$ (sandstone (small): cobble (medium): cobble (large), hereafter), $1: 2: 2,1: 3: 3$, and $1: 4: 4$ with average aggregate grain diameters of $26.7 \mathrm{~mm}$, $29 \mathrm{~mm}, 29.5 \mathrm{~mm}$, and $30.6 \mathrm{~mm}$, respectively, that correspond to the Sauter mean diameter [64]. Moreover, the hydromechanical tests were conducted, and corresponding results are presented in Figures 8 and 9, respectively.

Figure 8 shows that $k$ is positively correlated with particle size for different stress states for the media of the CCA with aggregate particle sizes in the range of $26.7 \sim 30.6 \mathrm{~mm}$ and $2 \mathrm{~mm}$ for fine sand; the curve is characterized by a relative smooth turning point at approximately $29 \mathrm{~mm}$. In addition, the maximum $k$ is $1.09 E-11 \mathrm{~m}^{2}$ in group 4 with a stress of $11.43 \mathrm{MPa}$ and a diameter of $30.6 \mathrm{~mm}$, while the minimum value is $3.847 E-12 \mathrm{~m}^{2}$ for group 1 corresponding to a stress of $4.38 \mathrm{MPa}$ and a diameter of $26.7 \mathrm{~mm}$. The experimental data are well fitted using (7) combined with the parameter of $\zeta_{2}$ and $\zeta_{3}$ in (19), and the associated parameter $\zeta_{1}$ is $2 a_{0}$ which ranges from $2.979 E-4$ to $6.347 E-4 ; m$ varies between 0.3544 and 0.4166 .

Considering the effects of the stress and porosity on $\beta$, the nonlinear regression calculations for $\beta$ were performed with different aggregate sizes using (8) and the parameters of $\zeta_{5}$ and $\zeta_{6}$ in (20). The results show that (8) is adequate for describing the changes in $\beta$ experimentally; the negative relationship between $\beta$ and the average particle size is represented by a linear relationship as shown in Figure 9. The corresponding parameter values for $b_{0}$ are in the range of 16.53 18.46, $c$ ranges between $1.01 E-6$ and $2.94 E-6$, and the values for $\zeta_{4}, \zeta_{5}$, and $\zeta_{6}$ are 2,2 , and 4 , respectively. In 


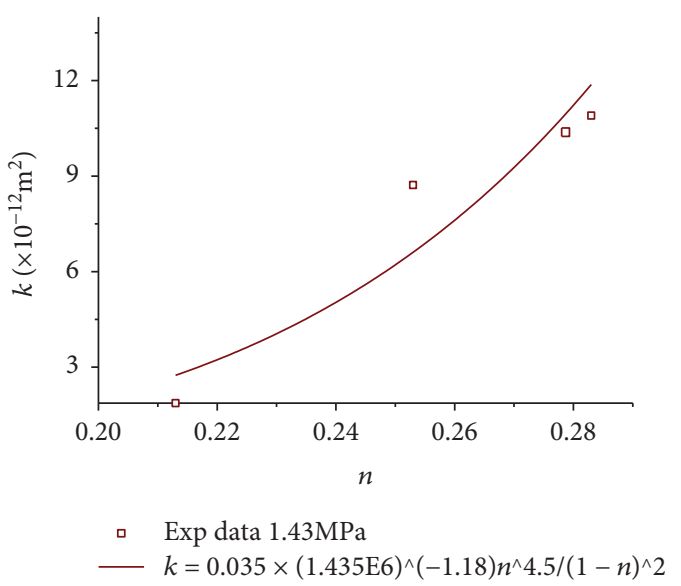

(a)

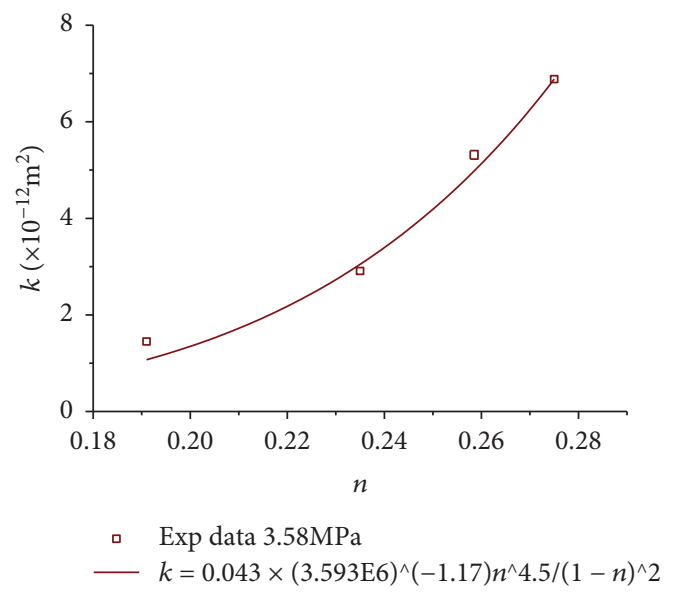

(c)

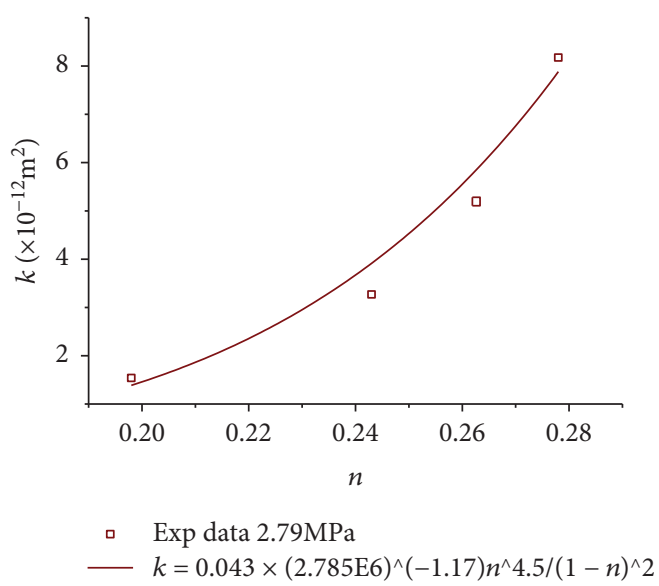

(b)

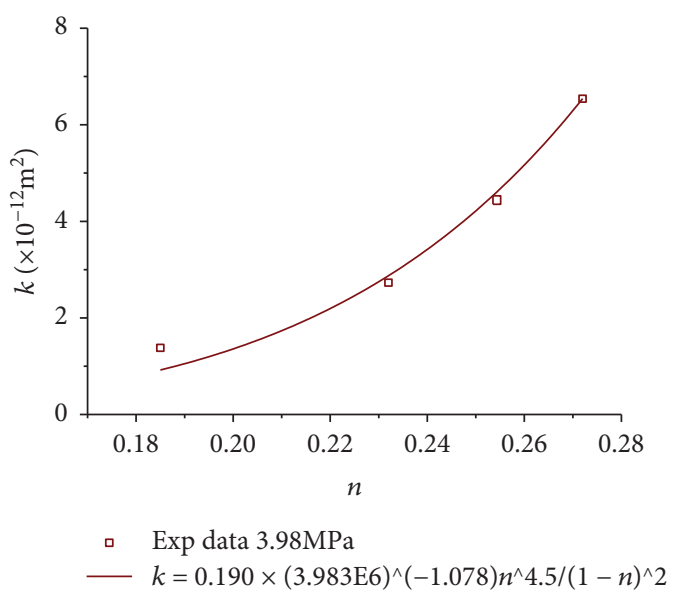

(d)

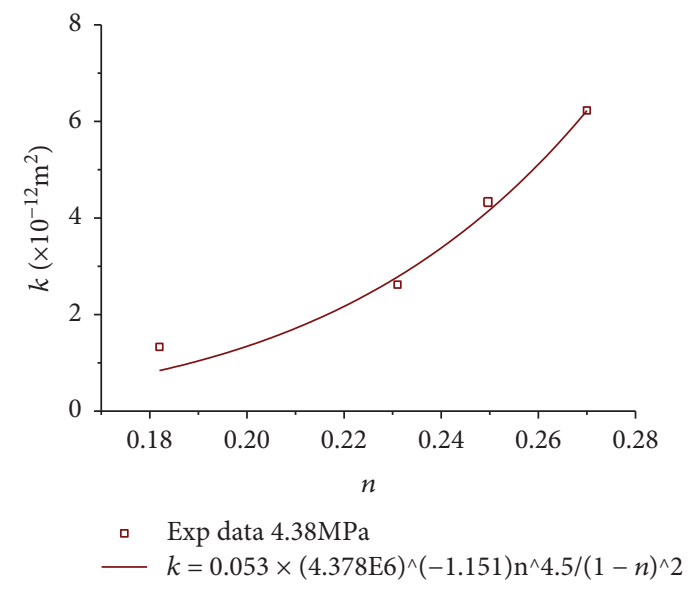

(e)

FIGURE 6: Intrinsic permeability characteristic with the influence of initial porosity under different stresses.

addition, regarding the integrated effects of the stress, particle size, and porosity, the maximum value of $\beta$ is $2.9 \mathrm{E} 8 \mathrm{~m}^{-1}$ in group 1 , the axial stress is $4.38 \mathrm{MPa}$, and the diameter is $26.7 \mathrm{~mm}$; the minimum value of $\beta$ is $0.918 \mathrm{E} 8 \mathrm{~m}^{-1}$ in group 4 with a stress value of $1.43 \mathrm{MPa}$ and a diameter of $30.6 \mathrm{~mm}$.

Considering the significant different responses of $k$ and $\beta$ to the aggregate size at a specific stress state, the results illustrate that the size ratio of the large particles to the fine sand plays a vital role in the changes in the internal structure of the CCA. As the aggregate size increases, more voids were created close to the surface of the large particle for the fine sand due to the wall effect of the large particles. In addition, the wedging effect caused by the fine sand was gradually diminished, resulting in the mediation of pore shape, 


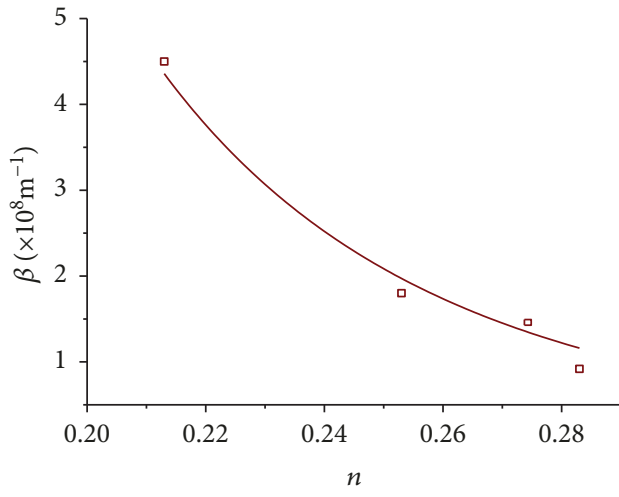

- Exp data 1.43MPa

$-\beta=243.4 \exp (3.124)(1-n) \wedge 2 / n^{\wedge} 4$

(a)

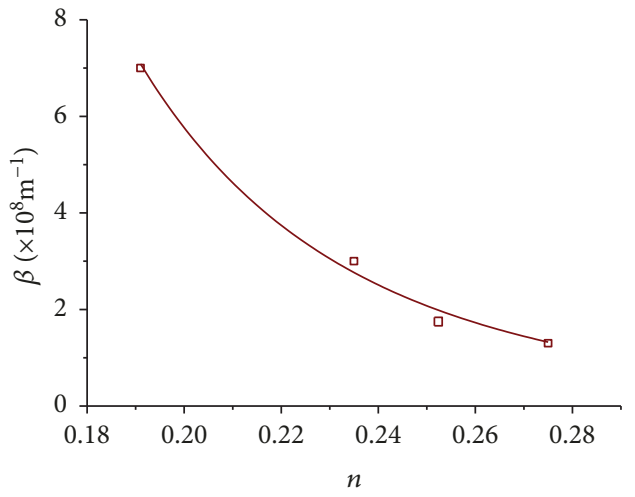

- $\quad$ Exp data $3.58 \mathrm{MPa}$

$-\beta=243 \exp (7.810)(1-n) \wedge 2 / n^{\wedge} 4$

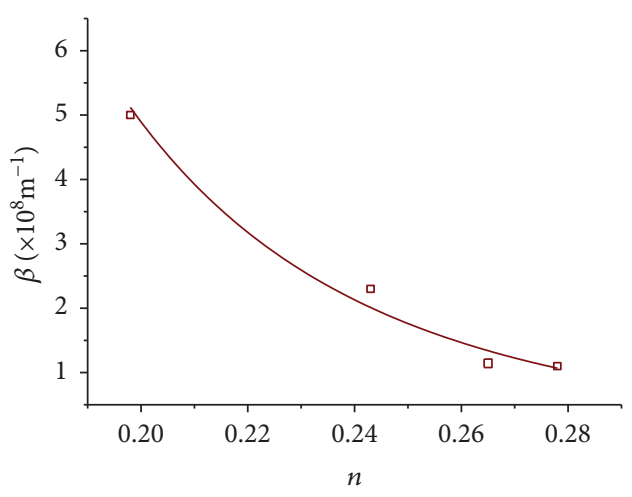

- $\quad$ Exp data $2.79 \mathrm{MPa}$

$-\beta=229.3 \exp (6.09)(1-n) \wedge 2 / n^{\wedge} 4$

(b)

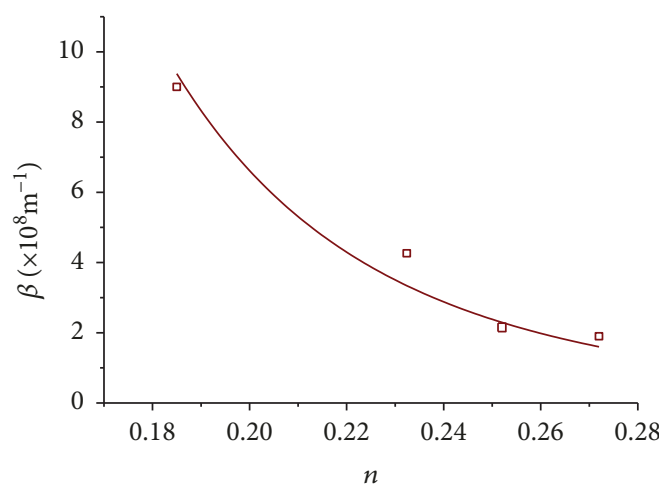

- $\quad$ Exp data $3.58 \mathrm{MPa}$

- $\beta=247.4 \exp (8.795)(1-n) \wedge 2 / n^{\wedge} 4$

(d)

(c)

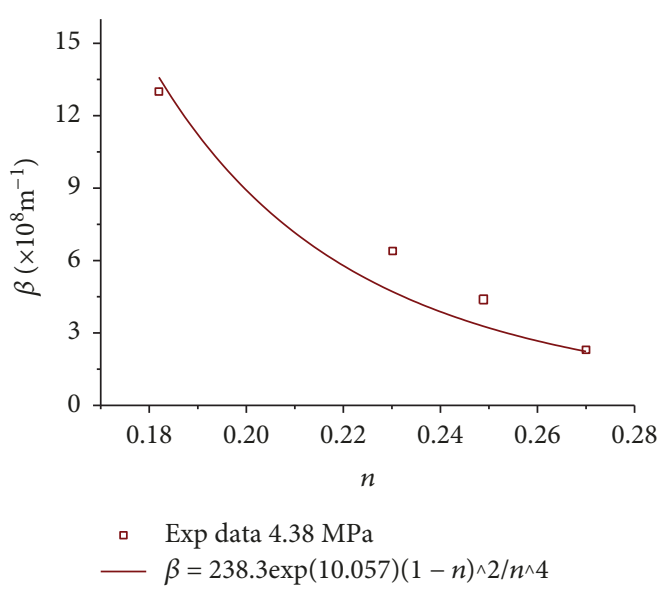

(e)

FIGURE 7: Inertial resistance $\beta$ characteristic with the influence of initial porosity under different stresses.

porethroat, and tortuosity. In contrast to the dominant effect of the fine sand on the viscosity and inertial losses, the increase in the aggregate particle size contributed to greater viscosity losses than the inertial losses; this indicates that, compared to the effect on shortening the flow pathways, the increase in aggregate size facilitated the growth of hydraulic conductivity channels. Eventually, the hydraulic loss caused by the viscosity and the inertial effect were reduced considerably and this was characterized by the changes in $k$ and $\beta$.

In addition, the globally optimized parameters of the particle diameter in (7) and (8) illustrate that, for this mixture, the stress did not contribute to the changes in $k$ and 


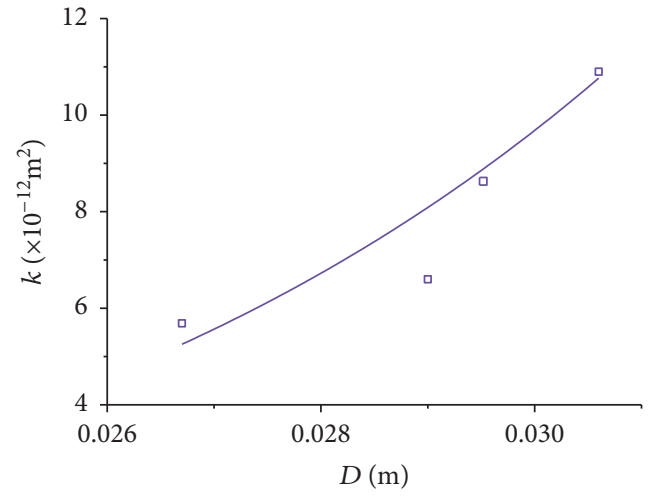

- $\quad$ Exp data 1.43 MPa $P=n^{\wedge} 4.5 /(1-n) \wedge 2$

$k=6.349 E-4 \times(1.433 \mathrm{E} 6) \wedge(-0.4165) D^{\wedge} 2 P$

(a)

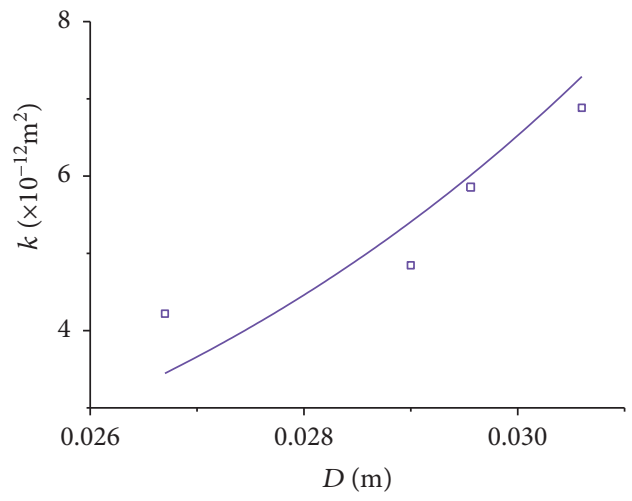

- Exp data $3.58 \mathrm{MPa} P=n \wedge 4.5 /(1-n) \wedge 2$

$-k=3.228 E-4 \times(3.583 \mathrm{E} 6) \wedge(-0.362) D \wedge 2 P$

(c)

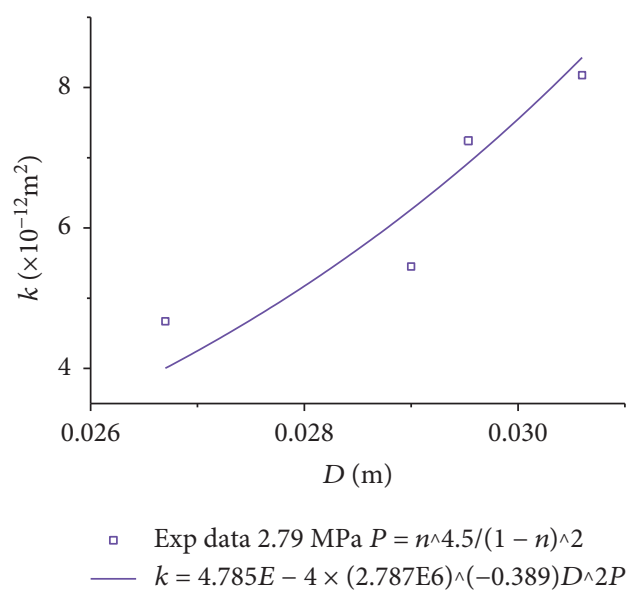

(b)

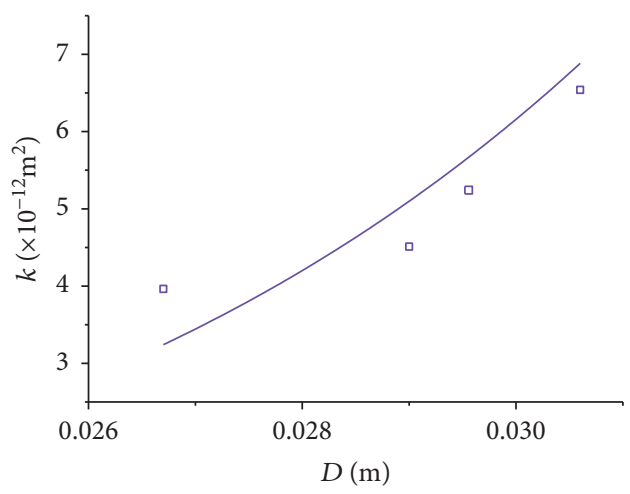

- $\quad$ Exp data $3.98 \mathrm{MPa} P=n^{\wedge} 4.5 /(1-n) \wedge 2$

$-k=2.976 E-4 \times(3.981 \mathrm{E} 6) \wedge(-0.3544) D^{\wedge} 2 P$

(d)

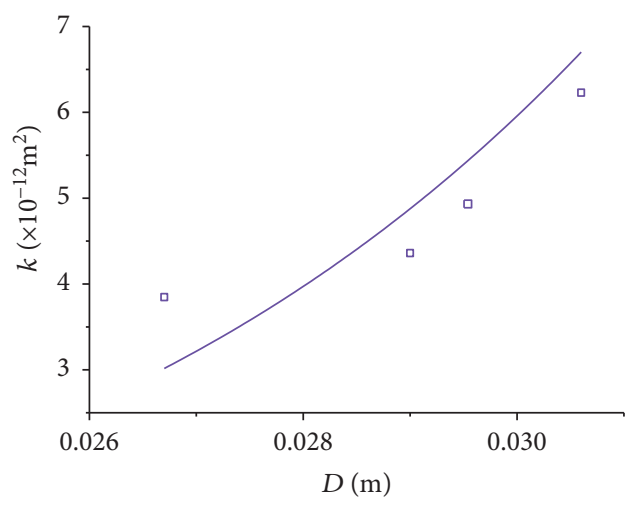

- $\quad$ Exp data $4.38 \mathrm{MPa} P=n^{\wedge} 4.5 /(1-n) \wedge 2$

$-k=3.765 E-4 \times 4.379 \mathrm{E} 6 \wedge(-0.3667) D^{\wedge} 2 P$

(e)

Figure 8: Intrinsic permeability characteristic with the influence of particle size and initial porosity under different stresses.

$\beta$ induced by the particle size. In contrast, the locally optimized parameters of stress $c$ varied within a small range from $1.01 E-6$ to $2.94 E-6$, illustrating that the stress effect depends on the particle size of the components and is characterized by a negative correlation between the stress sensitivity coefficient in the stress-dependent porosity function; the details of the function are shown in the stressporosity curve (group 1, group 2, and group 4) in Appendix A. Furthermore, the parameters of $a_{0}$ and $b_{0}$ represent the integrated effects of other attributes, such as the shape of 


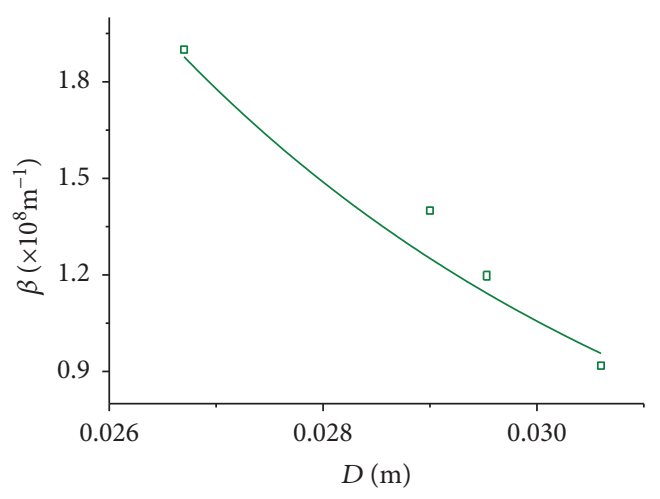

- Exp data $1.43 \mathrm{MPa} p=(1-n) \wedge 2 / n^{\wedge} 4$

$-\beta=16.54 \exp ((2.94 E-6) \times(1.433 \mathrm{E} 6))(1 / D) \wedge 2 p$

(a)

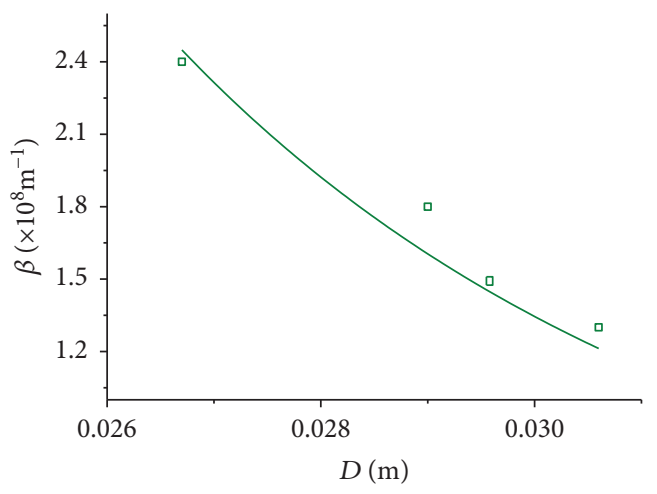

- Exp data $3.58 \mathrm{MPa} p=(1-n) \wedge 2 / n \wedge 4$

$-\beta=17.27 \exp ((1.19 E-6) \times(3.583 \mathrm{E} 6))(1 / D) \wedge 2 p$

(c)

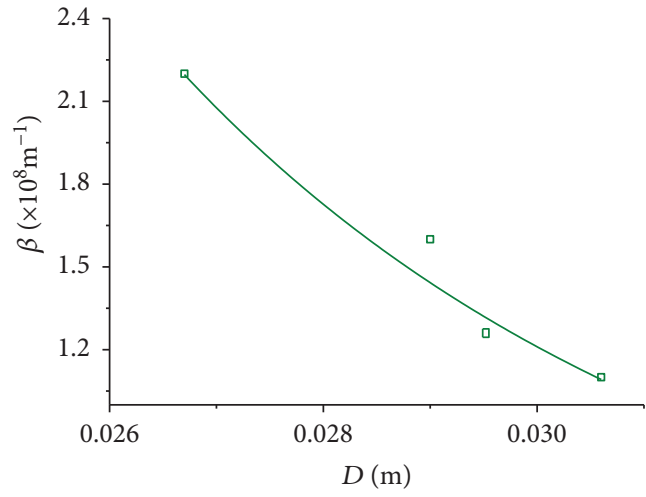

- Exp data $2.79 \mathrm{MPa} p=(1-n) \wedge 2 / n^{\wedge} 4$

$-\beta=16.87 \exp ((1.52 E-6) \times(12.787 \mathrm{E} 6))(1 / D) \wedge 2 p$

(b)

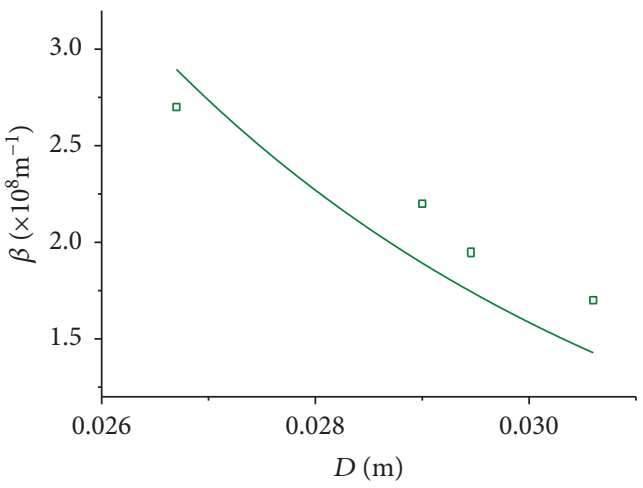

- Exp data 3.98 MPa $p=(1-n) \wedge 2 / n \wedge 4$

$-\beta=17.98 \exp ((1.09 E-6) \times(3.981 \mathrm{E} 6))(1 / D) \wedge 2 p$

(d)

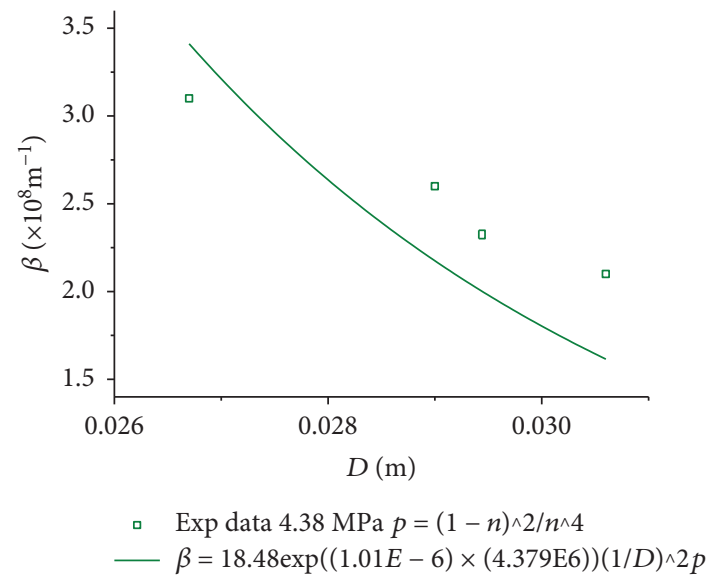

(e)

FIGURE 9: Inertial resistance $\beta$ characteristic with the influence of particle size and initial porosity under different stresses.

the particles and pores, the tortuosity, and the pore throat, which vary in a limited range.

A comparison of the behaviors of the CCA media with different size ratios and volume fractions under different stress states is shown in Figures 6-9. The results indicate that the stress significantly affected the $k$ and $\beta$ values by changing the number and magnitude of the conductivity channels bymediating the key coefficients such as porosity, pore shape, pore throat, and tortuosity; this occurred due to the movement of large particles and fine sand under the influence of the wedging and wall effects. The increase in the stress triggered the wedging of fine sand in the aggregate grain, which propagated to the void formed by the aggregate grain, leading to the reduction of the wall and wedging effects; as a result, a 
substantial number of conductivity paths were obstructed significantly and the flow pathways increased. For impermeable and nondeformable unconsolidated porous media, the compression process is comparable to the elastic deformation of consolidated material. Therefore, the changes in the internal structure were mainly caused by the movement of large and small particles under the influence of external dynamic stress. However, the specific mechanism is relatively complicated considering the wedging effect and the wall effect. It is possible that a transportation effect and a broken effect are caused by a high hydraulic gradient and high stress, respectively, although this issue remains open to discussion. Notably, although we have shown experimentally that there is an increasing trend of the viscous and inertial resistance relative to the increase in the stress, as the density increases, the changes in $k$ and $\beta$ may depend less on the stress unless the particles break due to the very high stress.

Concerning the complex interplay induced by the stress in this mixture, the correlation between $k, \beta$, porosity, stress, and other attributes is well characterized by (7) and (8) associated with the globally optimized parameters compared to the classical models. The classical models are mostly based on assumptions and simplifications of the geometry of the pore space for monosized single materials and the effects of the shape of the pore space and particles, the particle size ratio, and the volume fraction of the components are neglected in the mixture.

4.4. Model Evaluation. In order to verify the accuracy of the proposed model of $k, \beta$, and seepage discharge ((9)) using the power law of stress-porosity ("Appendix A") with the optimized key parameter values, a comparison between the modeled data and real-time discharge data was performed using the normalized objective function (NOF) and the slope $\gamma$ of the regression line, and a field measurement was conducted. It is beneficial to extend the proposed model to field applications such as water inrush assessment of destressing zones and disaster prediction for collapse columns in mining areas, tunnels, and relevant municipal engineering projects.

(1) The root mean square error (RMSE) and the NOF were incorporated with theoretical and experimental values and are defined as follows:

$$
\mathrm{RMSE}=\sqrt{\frac{\sum_{i=1}^{N}\left(V_{i}-v_{i}\right)^{2}}{N}},
$$

where $V_{i}$ is the experimental value corresponding to $i=1,2, \ldots, N, v_{i}$ is the prediction value according to (9) and corresponding to $i=1,2, \ldots, N$, and $N$ denotes the total number of points.

The NOF is the ratio of the RMSE to the mean value $V$ and is expressed as

$$
\mathrm{NOF}=\frac{\mathrm{RMSE}}{V},
$$

where $V=(1 / N) \sum_{i=1}^{N} V_{i}$ is the average value of the experimental data. It should be pointed out that the closer to 0 the NOF value is, the higher the accuracy for the predicted value is. Nevertheless, when the NOF value is less than 1.0, the discharge prediction model is still reliable and can be employed with sufficient accuracy $[66,67]$. The results are shown in Figure 10.

(2) The model is also verified by scattergrams of the prediction values versus the experimental values. Notably, the best result occurs when all points fall on a line with slope gradient of 1 . The deviation from that line is measured by fitting a regression line:

$$
y=\gamma x
$$

where $y$ and $x$ represent the prediction and experimental values, respectively. The slope $y$ in this line should be equal to 1.0 for a perfect agreement. If the slope $y$ is less than 1.0, the discharge model underestimates the experimental data; if the slope is greater than 1.0, the experimental values are overestimated. In addition, the coefficient of determination $R^{2}$ evaluates the accuracy of the match and represents the degree to which the regression line fits the data. The agreement is best at $R^{2}=1.0$ when none of the points are scattered around the line. The results are shown in Figure 11.

It can be observed from Figure 10 that the average NOF values for group 1 to group 6 are 9.58e-2, $4.38 \mathrm{e}-2, \quad 5.21 \mathrm{e}-1, \quad 9.37 \mathrm{e}-2, \quad 1.11 \mathrm{e}-1,2.59 \mathrm{e}-1$, and $2.17 \mathrm{e}-1$, respectively, which are less than 1.0. This suggests that the accuracy of the prediction values is acceptable; this is especially true for group 1, group 2, and group 3 with lower NOF values. For group 4 and group 5 at a stress of $4.38 \mathrm{MPa}$, the deviation of the prediction values is relatively large due to the influence of the deviation of the average aggregate diameter because of the partially broken aggregate; this result was attributed to a relatively high stress and a large volume fraction of the aggregate particle. In contrast, due to the presence of a larger amount of fine sand filling for group 6, the probability of the aggregate breaking under high stress was effectively reduced. However, this also generated a negative effect of a partial sedimentary phenomenon caused by the transportation effect due to a lower stress state and a high hydraulic gradient. As a result, there was a better and a worse match for $4.38 \mathrm{MPa}$ and $1.43 \mathrm{MPa}$, respectively, between the experimental data and the analytical solution.

Figure 11 indicates that the best agreement for the discharge is observed for group 2 at stress values of $1.43 \mathrm{MPa}, \quad 2.79 \mathrm{MPa}, \quad 3.58 \mathrm{MPa}, \quad 3.98 \mathrm{MPa}$, and 

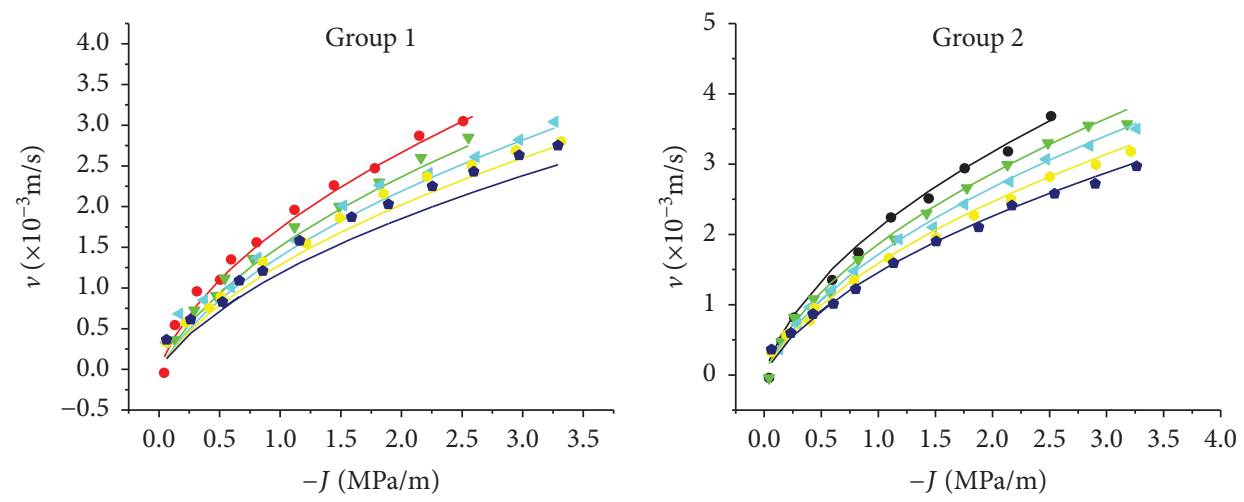

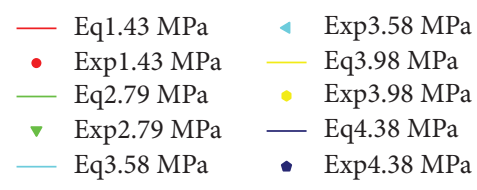

(a)

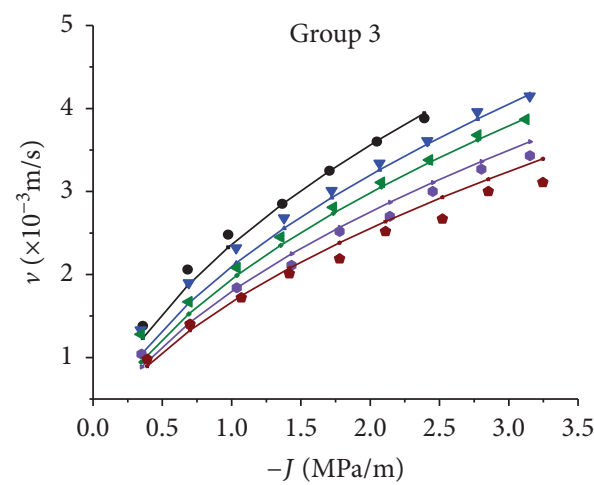

(c)

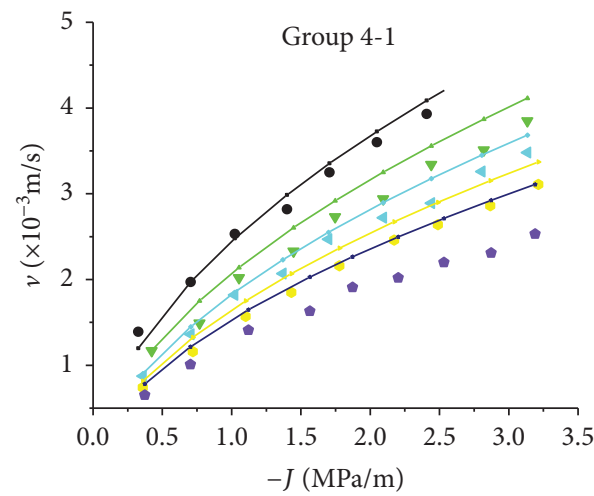

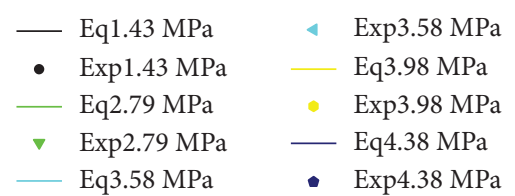

(b)

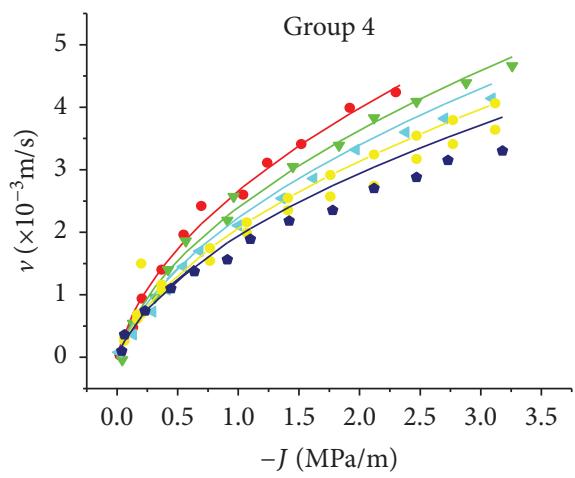

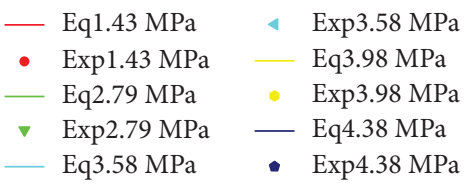

(d)

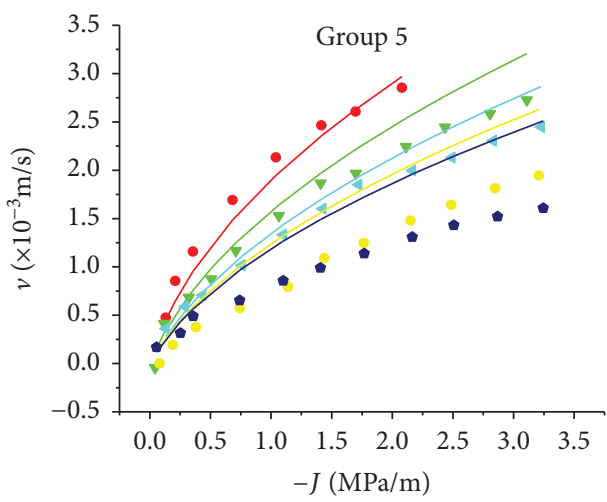

$\begin{array}{llll}- & \text { Eq1.43 MPa } & \text { Exp3.58 MPa } \\ - & \text { Exp1.43 MPa } & \text { Eq3.98 MPa } \\ \text { Eq2.79 } \mathrm{MPa} & \text { Exp3.98 MPa } \\ \checkmark & \text { Exp2.79 MPa — } & \text { Eq4.38 MPa } \\ - & \text { Eq3.58 MPa } & \text { Exp4.38 MPa }\end{array}$

(f)

(e)

FIgure 10: Continued. 


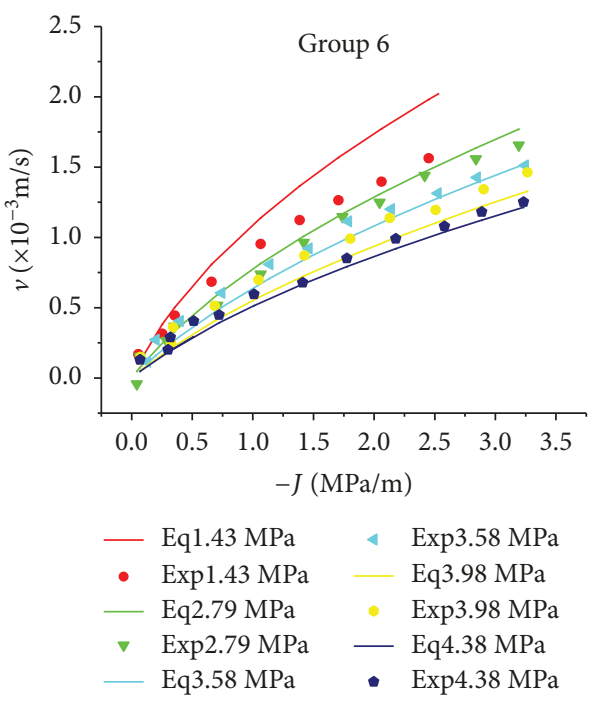

(g)

FIgURE 10: Result of comparison between predicated value and measured value.

4.38 MPa with $R^{2}$ values of $0.993,0.994,0.998,0.995$, and 0.995 and slopes $\gamma$ of $1.028,1.014,1.012,1.023$, and 1.016, respectively. Better agreements are also observed for group 1 and group 4 with slopes close to 1 and $R^{2}$ values greater than 0.95 . Additionally, the slope values for group 6 and group 5 also approached 1 with $R^{2}$ values greater than 0.95 , except the points of $1.43 \mathrm{MPa}$ in group 6 and $3.98 \mathrm{MPa}$ and $4.38 \mathrm{MPa}$ in group 5.

(3) The validity of the model for the field measurement. To determine the field application of the CCA models, the Tarangaole-Colliery located in the Ordos Basin was selected; the seepage behavior of the CCA of a Cretaceous system located at a depth of $207 \sim 604 \mathrm{~m}$ directly above the coal seam was investigated by a field pumping test. The transmissivity of the CCA characterized by the equivalent intrinsic permeability was calculated based on field measurement data.

$$
\bar{k}=\frac{0.366 Q \rho g}{M S \mu} \lg \frac{R}{r},
$$

where $\bar{k}\left[\mathrm{~L}^{2}\right]$ is the equivalent intrinsic permeability, $Q\left[\mathrm{~L}^{3} \mathrm{~T}^{-1}\right]$ is the pumping rate, $r[\mathrm{~L}]$ is the well radius, $R[\mathrm{~L}]$ is the influence radius, $M[\mathrm{~L}]$ is the thickness of the confined aquifer, and $S[\mathrm{~L}]$ is the aquifer drawdown.

In detail, 13 test boreholes were drilled and ten available sets of data were obtained from the pumping tests, as shown in Figure 12. The predicted data of the equivalent intrinsic permeability as formulated by the models of $k$ and $\beta$ were used to evaluate the transmissivity of the test area; the detailed results are shown in Figure 12.

$$
\bar{k}=\left(\frac{1}{k}+\frac{\beta \rho v}{\mu}\right)^{-1} .
$$

It is evident from Figure 12 that the in situ permeability differs for the maximum and the minimum modeled data; in addition, the difference between the predicted data and the in situ data is limited to the magnitude of $10^{-13} \mathrm{~m}^{2}$, illustrating that the accuracy of the proposed CCA models meets the engineering requirements.

Based on these results, we can conclude that the CCA models incorporating a discharge model and the models of $k$ and $\beta$ are suitable for describing the seepage behavior and the characteristics of the CCA.

\section{Discussion}

The motivation of this paper is to consider the effects of the components, hydromechanics, and geomechanics, to study the Forchheimer coefficients and seepage characteristics for the CCA. Compared to multimixture studies focusing on binary mixtures $[63,64]$ and ternary mixtures [68] owning properties similar to the CCA media and investigations that focused on the changes in the porosity and permeability caused by the components of porous media, in this study, we experimentally determined the Forchheimer coefficients and obtained seepage characteristics of the CCA. In detail, seepage behavior and associated characteristic of the CCA were studied using the Forchheimer law under different hydrogeologyical conditions; empirical models of the CCA characterized by the models of intrinsic permeability $(k)$, inertial resistance $(\beta)$, and seepage discharge were developed, and the validities were confirmed through experimental 


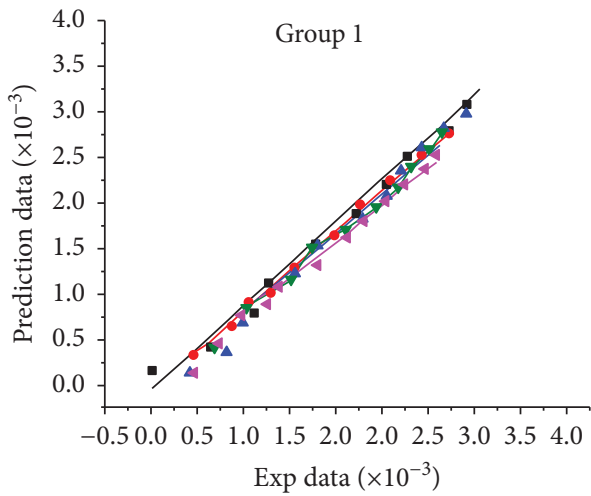

- $180 \mathrm{kN}$ data $-y=1.018 \times R^{2}=0.853$

- $350 \mathrm{kN}$ data $-y=0.957 x R^{2}=0.997$

$\triangle 450 \mathrm{kN}$ data $-y=0.955 x R^{2}=0.982$

- $500 \mathrm{kN}$ data $-y=0.933 \times R^{2}=0.989$

4 $550 \mathrm{kN}$ data $-y=0.884 x R^{2}=0.989$

(a)

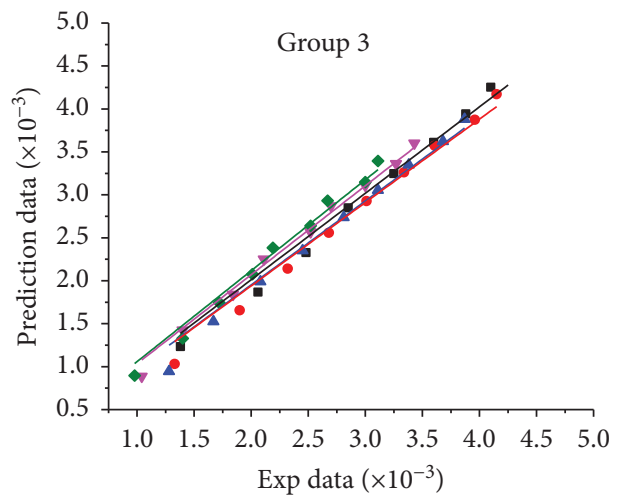

- $1.43 \mathrm{MPa}$

- $2.79 \mathrm{MPa}$

\ $3.58 \mathrm{MPa}$

- $3.98 \mathrm{MPa}$

- $4.38 \mathrm{MPa}$

- $y=1.058 \times R^{2}=0.986$

- $y=1.006 \times R^{2}=0.988$

- $y=0.976 \times R^{2}=0.984$

- $y=1.035 \times R^{2}=0.992$

- $y=0.97 \times R^{2}=0.984$

(c)

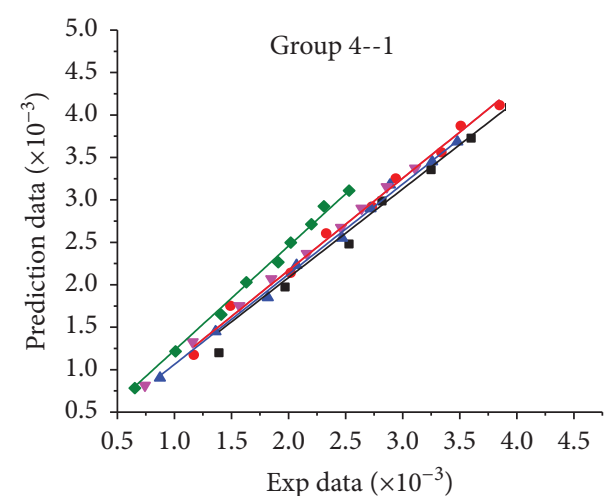

- $1.43 \mathrm{MPa}-y=1.288 \times R^{2}=0.995$

- $2.79 \mathrm{MPa}-y=1.085 \times R^{2}=0.993$

$\triangle 3.58 \mathrm{MPa}-y=1.061 \times R^{2}=0.996$

- $3.98 \mathrm{MPa}-y=1.0428 x R^{2}=0.988$

- $4.38 \mathrm{MPa}-y=1.085 x R^{2}=0.993$

(e)

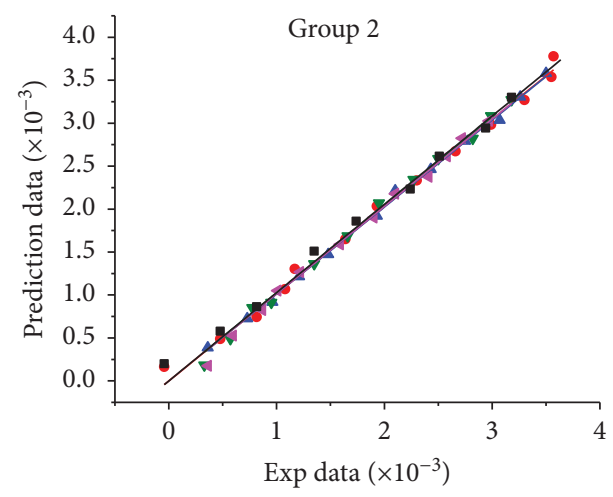

- $1.43 \mathrm{MPa}$ data $-y=1.028 \times R^{2}=0.993$

- $2.79 \mathrm{MPa}$ data $-y=1.014 \times R^{2}=0.994$

$\triangle 3.58 \mathrm{MPa}$ data $-y=1.012 x R^{2}=0.998$

- $3.98 \mathrm{MPa}$ data $-y=1.023 \times R^{2}=0.995$

4 4.38 MPa data $-y=1.016 x R^{2}=0.995$

(b)

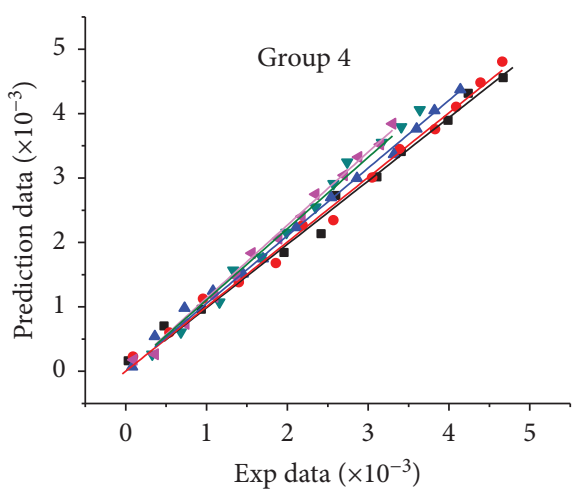

- $1.43 \mathrm{MPa}$ data $-y=0.985 x R^{2}=0.992$

- $2.79 \mathrm{MPa}$ data $-y=1.003 \times R^{2}=0.991$

$\triangle 3.58 \mathrm{MPa}$ data $-y=1.052 x R^{2}=0.994$

- $3.98 \mathrm{MPa}$ data $-y=1.134 \times R^{2}=0.994$

4 $4.38 \mathrm{Mpa}$ data $-y=1.106 x R^{2}=0.931$

(d)

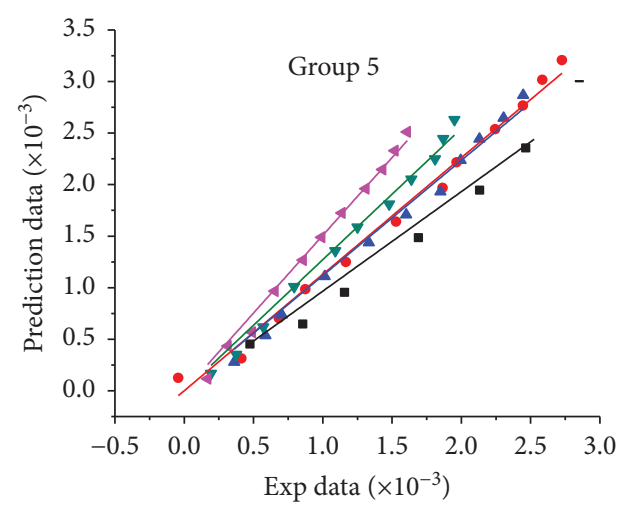

- $1.43 \mathrm{MPa}$ data $-y=0.967 \times R^{2}=0.976$

- $2.79 \mathrm{MPa}$ data $-y=1.130 \times R^{2}=0.991$

$\triangle 3.58 \mathrm{MPa}$ data $-y=1.118 \times R^{2}=0.989$

- $3.98 \mathrm{MPa}$ data $-y=1.271 \times R^{2}=0.990$

4 $4.38 \mathrm{MPa}$ data $-y=1.508 \times R^{2}=0.991$

(f)

Figure 11: Continued. 


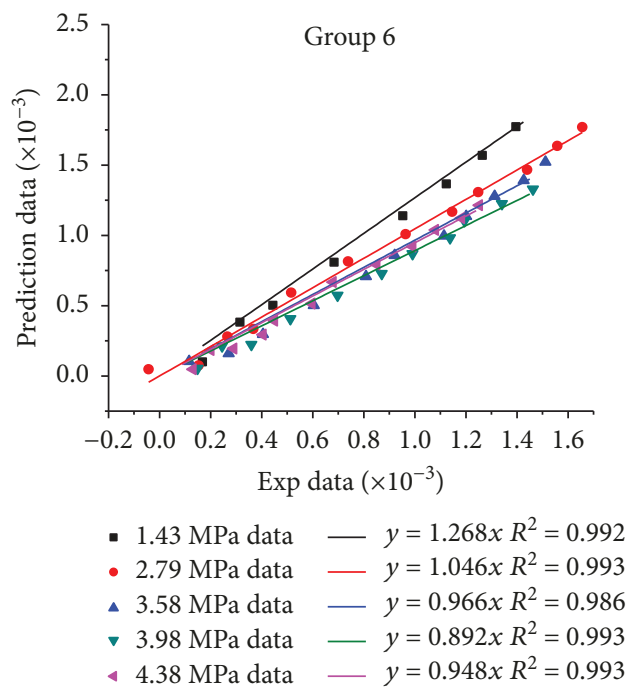

(g)

FigURE 11: Scattergrams of predictable and experimental value of discharge for conglomerate confined aquifer.
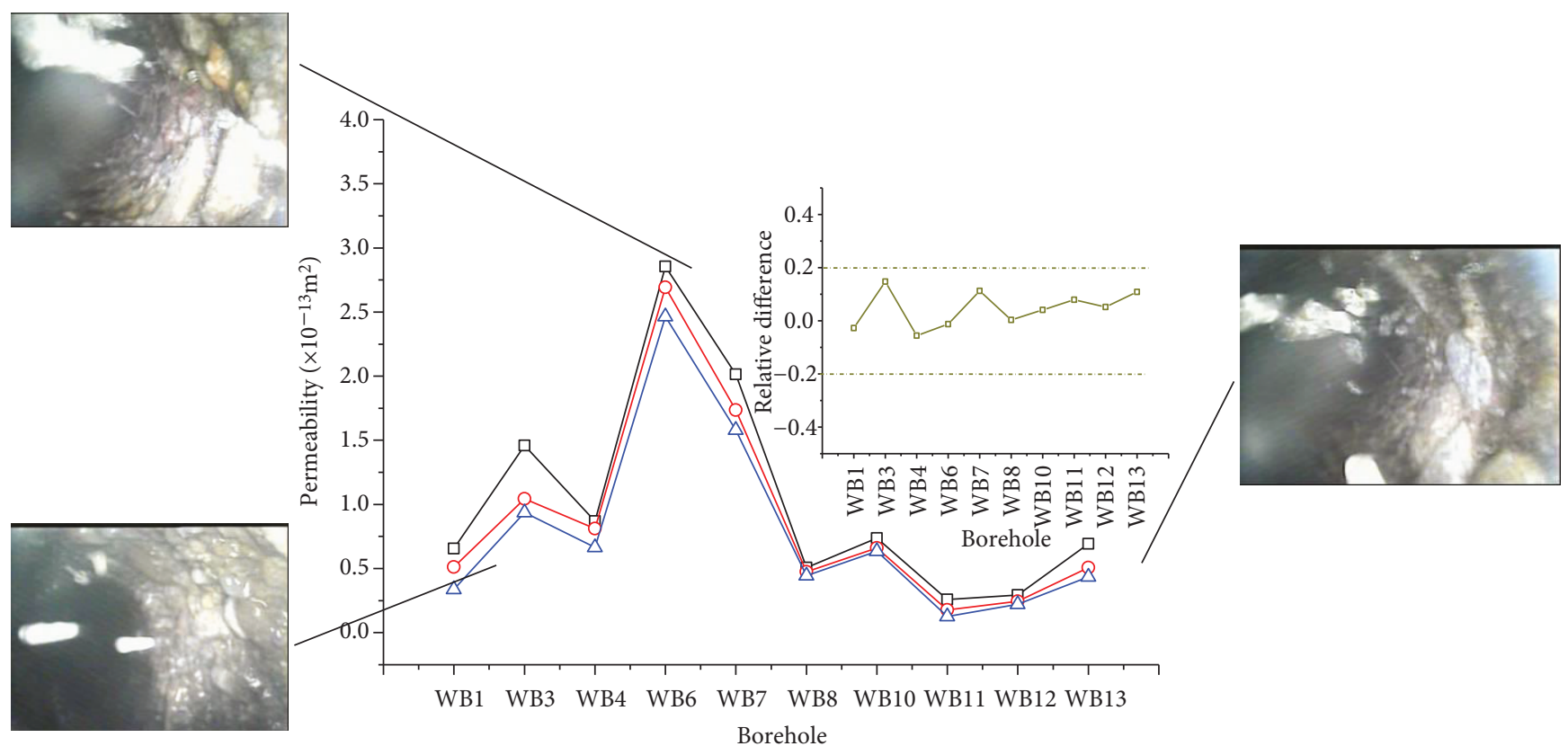

$\neg-$ Maximum model data

- - In situ data

$\neg-$ Minimum model data

FIGURE 12: Comparison of model and in situ measure value of the permeability for conglomerate confined aquifer.

and field measurement data; the aggregate grain and filling material of the CCA had positive and negative effects on the interconnected channels, respectively, accompanied by wedging and wall effects; and the transportation effect and broken effect occurred for the lower and higher in situ stress situations and contributed to the shrinkage of the interconnected pores.

However, this study was limited by the laboratory-based evaluation of a one-dimensional isotropic porous media, a steady flow, and the change moment of the stress was limited to zero hydraulic gradient. In order to upscale the research results effectively to in situ field conditions, future research should be focused on the field of anisotropic porous media and considering the HM effects under an unsteady fluid flow. Nevertheless, the results still provide available Forchheimer coefficients for CCA and significant insights into the evolution of the internal structure of CCA composed of the different particle sizes and volume fractions 
of the components under the effect of stress and a reference for theoretical and numerical simulation studies for the prevention and control of geological disasters and for energy development.

\section{Summary and Conclusions}

In this study, we developed empirical models of $k, \beta$, and seepage discharge for a CCA. Subsequently, two comparative sets of hydromechanical experiments of porous media comprised of seven groups were conducted. The first experiment evaluated the impact of the initial porosity and was conducted with different quantities of filling material; the particle size effect was obtained in the second experiment, considering the stress and the hydraulic gradient.

The following key conclusions were obtained.

(1) The seepage behavior of the CCA was characterized by a non-Darcy flow, and $k$ and $\beta$ were affected by the initial porosity, particle size, and stress. The stress affected $k$ and $\beta$ in terms of power and exponential functions, respectively, and the porosity and intrinsic permeability decreased in response to the increase in the stress, while $\beta$ exhibited an increasing trend accompanied by progressively larger increments. The transportation effect and broken effect that occurred in the lower and higher stress situations contributed to the shrinkage of the interconnected voids, resulting in the changes in $k$ and $\beta$. An increase in $k$ in the power function was related to an increase in the porosity and the aggregate size, while the opposite response was observed for $\beta$.

(2) The wall and wedging effects were determined, and the CCA was characterized by the interaction of the components and the stress. The stress affected the internal structure of the components by the movement of fine sand and aggregate particle and changed the quantity and magnitude of the conductivity channels, resulting in the reduction of the conductivity and a weakening in the wedging and wall effects in the CCA. The components of the CCA contributed to the changes in $k$ and $\beta$ induced by the stress. The combination of a small aggregate size and a large volume fraction of fine sand exhibited a larger stress response than the combination of a large aggregate size and a small volume fraction of fine sand.

(3) The discharge model of the CCA was positively correlated with the hydraulic gradient, the aggregate size, and the initial porosity and negatively correlated with the stress. The comparison between the experimental results, field investigation data, and the modeled values validated the application of the CCA models.

\section{Greek Symbols}

$v:$

Flow velocity Intrinsic permeability

$\begin{array}{ll}\mu: & \text { Dynamic viscosity } \\ \beta: & \text { Non-Darcy coefficient } \\ g: & \text { Gravity acceleration } \\ \omega: & \text { Exponent coefficient } \\ \lambda: & \text { Generalized resistance coefficient } \\ \sigma_{0}: & \text { Initial effective stress } \\ \sigma: & \text { Effective stress } \\ k_{0}: & \text { Initial intrinsic permeability } \\ \gamma: & \text { Stress sensitivity coefficient } \\ \tau: & \text { Stress sensitivity coefficient } \\ \zeta: & \text { Exponent coefficient } \\ \eta: & \text { Attribute parameter of porous media } \\ \zeta_{1}: & \text { Particle diameter coefficient } \\ \zeta_{4}: & \text { Particle diameter coefficient } \\ \zeta_{2}: & \text { Porosity coefficient } \\ \zeta_{3}: & \text { Porosity coefficient } \\ \zeta_{5}: & \text { Porosity coefficient } \\ \zeta_{6}: & \text { Porosity coefficient } \\ \rho_{1}, \rho_{2,} \ldots, \rho_{n}: & \text { Density of different materials } \\ \gamma: & \text { The slope of the line } \\ \theta: & \text { Characteristic length of the porous media. }\end{array}$

\section{Nomenclature}

\begin{tabular}{|c|c|}
\hline$m:$ & Stress parameter \\
\hline$J:$ & Hydraulic gradient \\
\hline A: & Non-Darcy coefficient \\
\hline$B:$ & Non-Darcy coefficient \\
\hline$h:$ & Material coefficient \\
\hline$c:$ & Stress sensitivity parameter \\
\hline$a_{0}:$ & Initial attribute parameter \\
\hline$b_{0}:$ & Initial attribute parameter \\
\hline$c_{0}:$ & Initial attribute parameter \\
\hline$b:$ & Material constant \\
\hline$d:$ & Particle diameter \\
\hline$a:$ & Material constant \\
\hline Fo: & Forchheimer number \\
\hline Re: & Reynolds number \\
\hline$f:$ & Initial attribute parameter \\
\hline$E:$ & Non-Darcy effect \\
\hline$h_{s}:$ & Height of the mixture \\
\hline$d:$ & Diameter of the porous media \\
\hline$D:$ & Diameter of the aggregate particle \\
\hline$d^{*}:$ & Diameter of cylinder \\
\hline$v_{\varphi}:$ & Volume of the pore \\
\hline$n:$ & Medium porosity \\
\hline$n_{0}:$ & Initial medium porosity \\
\hline$m_{1}, m_{2} \ldots, m_{n}$ & Material qualities \\
\hline$h_{t}:$ & Displacement of loading head \\
\hline$R^{2}:$ & Determination coefficient \\
\hline$a_{1}:$ & Property parameter \\
\hline$b_{1}:$ & Attribute coefficient \\
\hline$v_{i}:$ & Prediction values \\
\hline$V_{i}:$ & Experimental values \\
\hline$y:$ & Prediction value \\
\hline$x:$ & Experimental value \\
\hline $\bar{k}:$ & Equivalent intrinsic permeability \\
\hline Q: & Pumping rate \\
\hline & Well rac \\
\hline
\end{tabular}



$R:$
$M:$
Influence radius
$S:$
Thickness of the confined aquifer Aquifer drawdown.

\section{Abbreviations}

RMSE: Root mean square error

NOF: Normalized objective function.

\section{Data Availability}

The data used to support the findings of this study are available from the corresponding author upon request.

\section{Conflicts of Interest}

The authors declare that there are no conflicts of interest regarding the publication of this paper.

\section{Acknowledgments}

The research is financially supported by the National Key Research and Development Program of China (No. 2016YFC0801401 and No. 2016YFC0600708), Major Consulting Project of Chinese Academy of Engineering (No. 2017-ZD-2), Yue Qi Distinguished Scholar Project of China University of Mining \& Technology (Beijing), and Fundamental Research Funds for the Central Universities (No. 2009QM01).

\section{Supplementary Materials}

(1) Hydraulic gradient $(-J)$ versus discharge $(v)$ curves: the plots of hydraulic gradient versus discharge for the another four conglomerate confined aquifer media at various axial stresses. (2) Porosity $(n)$ versus stress $(\sigma)$ curves. (Supplementary Materials)

\section{References}

[1] X. Wang and J. J. Sheng, "Effect of low-velocity non-Darcy flow on well production performance in shale and tight oil reservoirs," Fuel, vol. 190, pp. 41-46, 2017.

[2] C. Wang, Z.-P. Li, H. Li, Q. Wei, and R. T. Bai, "A new method to calculate the productivity of fractured horizontal gas wells considering non-Darcy flow in the fractures," Journal of Natural Gas Science and Engineering, vol. 26, pp. 981-991, 2015.

[3] N. Vishnu Ganesh, A. K. Abdul Hakeem, and B. Ganga, "Darcy-Forchheimer flow of hydromagnetic nanofluid over a stretching/shrinking sheet in a thermally stratified porous medium with second order slip, viscous and Ohmic dissipations effects," Ain Shams Engineering Journal, 2016.

[4] S. E. Ahmed, "Mixed convection in thermally anisotropic nonDarcy porous medium in double lid-driven cavity using Bejan's heatlines," Alexandria Engineering Journal, vol. 55, no. 1, pp. 299-309, 2016.

[5] Q. Lei, Characterisation and Modelling of Natural Fracture Networks: Geometry, Geomechanics and Fluid Flow, Imperial College London, 2016.

[6] S. Liu, Y. Wang, and S. Harpalani, "Anisotropy characteristics of coal shrinkage/swelling and Its impact on coal permeability evolution with $\mathrm{CO}_{2}$ injection," Greenhouse Gases: Science and Technology, vol. 6, no. 5, pp. 615-632, 2016.

[7] J. Taron and D. Elsworth, "Thermal-hydrologic-mechanicalchemical processes in the evolution of engineered geothermal reservoirs," International Journal of Rock Mechanics and Mining Sciences, vol. 46, no. 5, pp. 855-864, 2009.

[8] Y. Zhou, J. Helland, and D. G. Hatzignatiou, "Pore-scale modeling of waterflooding in mixed-wet-rock images: effects of initial saturation and wettability," SPE Journal, vol. 19, no. 1, pp. 88-100, 2014.

[9] J. Wang, X. Liu, Y. Wu et al., "Field experiment and numerical simulation of coupling non-Darcy flow caused by curtain and pumping well in foundation pit dewatering," Journal of Hydrology, vol. 549, pp. 277-293, 2017.

[10] M. Lebeau and J.-M. Konrad, "Non-Darcy flow and thermal radiation in convective embankment modeling," Computers and Geotechnics, vol. 73, pp. 91-99, 2016.

[11] R. Ganapathy and A. Mohan, "Thermo-diffusive Darcy flow induced by a concentrated source," Ain Shams Engineering Journal, vol. 7, no. 4, pp. 1069-1078, 2016.

[12] R. Ganapathy and A. Mohan, "Double diffusive Darcy flow induced by a spherical source," Ain Shams Engineering Journal, vol. 6, no. 2, pp. 661-669, 2015.

[13] R. Masson, L. Trenty, and Y. Zhang, "Coupling compositional liquid gas Darcy and free gas flows at porous and free-flow domains interface," Journal of Computational Physics, vol. 321, pp. 708-728, 2016.

[14] Z. Ye, D. Chen, and J. G. Wang, "Evaluation of the non-Darcy effect in coalbed methane production," Fuel, vol. 121, pp. 1-10, 2014.

[15] F. Zeng and G. Zhao, "Gas well production analysis with non-Darcy flow and real-gas PVT behavior," Journal of Petroleum Science and Engineering, vol. 59, no. 3-4, pp. 169-182, 2007.

[16] J. Wang, J. Xu, Y. Wang, and H. Li, "A new production predicting model of fractured horizontal wells in dualporosity gas reservoirs on non-Darcy flow conditions," Journal of Petroleum Science and Engineering, vol. 146, pp. 670-676, 2016.

[17] J. G. Wang, A. Kabir, J. Liu, and Z. Chen, "Effects of non-Darcy flow on the performance of coal seam gas wells," International Journal of Coal Geology, vol. 93, pp. 62-74, 2012.

[18] Z. Chen, J. Liu, D. Elsworth, Z. Pan, and S. Wang, "Roles of coal heterogeneity on evolution of coal permeability under unconstrained boundary conditions," Journal of Natural Gas Science and Engineering, vol. 15, pp. 38-52, 2013.

[19] S. Wang, D. Elsworth, and J. Liu, "Permeability evolution in fractured coal: the roles of fracture geometry and watercontent," International Journal of Coal Geology, vol. 87, no. 1, pp. 13-25, 2011.

[20] S. Baechler, J. M. Lavanchy, G. Armand, and M. Cruchaudet, "Characterisation of the hydraulic properties within the EDZ around drifts at level- $490 \mathrm{~m}$ of the Meuse/haute-Marne URL: a methodology for consistent interpretation of hydraulic tests," Physics and Chemistry of the Earth, Parts $A / B / C$, vol. 36, no. 17-18, pp. 1922-1931, 2011.

[21] R. De La Vaissière, G. Armand, and J. Talandier, "Gas and water flow in an excavation-induced fracture network around an underground drift: a case study for a radioactive waste repository in clay rock," Journal of Hydrology, vol. 521, pp. 141-156, 2015. 
[22] P. Wang, L. Jiang, J. Jiang, P. Zheng, and W. Li, "Strata behaviors and rock burst-inducing mechanism under the coupling effect of a hard, thick stratum and a normal fault," International Journal of Geomechanics, vol. 18, no. 2, article 04017135, 2018.

[23] D.-x. Liang, Z. Q. Jiang, S. Y. Zhu, Q. Sun, and Z. W. Qian, "Experimental research on water inrush in tunnel construction," Natural Hazards, vol. 81, no. 1, pp. 467480, 2016.

[24] T. H. Yang, W. H. Shi, S. C. Li, X. Yang, and B. Yang, "State of the art and trends of water-inrush mechanism of nonlinear flow in fractured rock mass," Journal of China Coal Society, vol. 41, no. 7, pp. 1598-1609, 2016.

[25] D. Ma, X. Miao, H. Bai et al., "Effect of mining on shear sidewall groundwater inrush hazard caused by seepage instability of the penetrated karst collapse pillar," Natural Hazards, vol. 82, no. 1, pp. 73-93, 2016.

[26] E. Ghane, N. R. Fausey, and L. C. Brown, "Non-Darcy flow of water through woodchip media," Journal of Hydrology, vol. 519, pp. 3400-3409, 2014.

[27] X. Kong, E. Wang, Q. Liu et al., "Dynamic permeability and porosity evolution of coal seam rich in CBM based on the flow-solid coupling theory," Journal of Natural Gas Science and Engineering, vol. 40, pp. 61-71, 2017.

[28] M. Zou, C. Wei, Z. Huang, and S. Wei, "Porosity type analysis and permeability model for micro-trans-pores, meso-macro-pores and cleats of coal samples," Journal of Natural Gas Science and Engineering, vol. 27, pp. 776784, 2015.

[29] R. Zhang, Z. Ning, F. Yang, H. Zhao, and Q. Wang, "A laboratory study of the porosity-permeability relationships of shale and sandstone under effective stress," International Journal of Rock Mechanics and Mining Sciences, vol. 81, pp. 19-27, 2016.

[30] D. Chen, Z. Pan, Z. Ye, B. Hou, D. Wang, and L. Yuan, "A unified permeability and effective stress relationship for porous and fractured reservoir rocks," Journal of Natural Gas Science and Engineering, vol. 29, pp. 401-412, 2016.

[31] X. Tan, H. Konietzky, and T. Frühwirt, "Laboratory observation and numerical simulation of permeability evolution during progressive failure of brittle rocks," International Journal of Rock Mechanics and Mining Sciences, vol. 68, pp. 167-176, 2014.

[32] B. T. Greenly and D. M. Joy, "One-dimensional finite-element model for high flow velocities in porous media," Journal of Geotechnical Engineering, vol. 122, no. 10, pp. 789-796, 1996.

[33] K. N. Moutsopoulos, "One-dimensional unsteady inertial flow in phreatic aquifers induced by a sudden change of the boundary head," Transport in Porous Media, vol. 70, no. 1, pp. 97-125, 2007.

[34] M. Sedghi-Asl, H. Rahimi, and R. Salehi, "Non-Darcy flow of water through a packed column test," Transport in Porous Media, vol. 101, no. 2, pp. 215-227, 2014.

[35] M. Sedghi-Asl, J. Farhoudi, H. Rahimi, and S. Hartmann, “An analytical solution for 1-D non-Darcy flow through slanting coarse deposits," Transport in Porous Media, vol. 104, no. 3, pp. 565-579, 2014.

[36] Z. Zeng and R. Grigg, "A criterion for non-Darcy flow in porous media," Transport in Porous Media, vol. 63, no. 1, pp. 57-69, 2006.
[37] M. Panfilov and M. Fourar, "Physical splitting of nonlinear effects in high-velocity stable flow through porous media," Advances in Water Resources, vol. 29, no. 1, pp. 30-41, 2006.

[38] P. Macini, E. Mesini, and R. Viola, "Laboratory measurements of non-Darcy flow coefficients in natural and artificial unconsolidated porous media," Journal of Petroleum Science and Engineering, vol. 77, no. 3-4, pp. 365-374, 2011.

[39] H. Yamada, F. Nakamura, Y. Watanabe, M. Murakami, and T. Nogami, "Measuring hydraulic permeability in a streambed using the packer test," Hydrological Processes, vol. 19, no. 13, pp. 2507-2524, 2005.

[40] D. Zhang, G. Fan, L. Ma, and X. Wang, "Aquifer protection during longwall mining of shallow coal seams: a case study in the Shendong coalfield of China," International Journal of Coal Geology, vol. 86, no. 2-3, pp. 190-196, 2011.

[41] L. Dong, F. Xia, F. Nie, Z. Yan, C. Zhang, and M. Li, "Petrology characteristics of Nalinggou uranium deposit in Ordos Basin," Advances in Geosciences, vol. 6, no. 4, pp. 297-306, 2016.

[42] J.-J. Dong, J.-Y. Hsu, W.-J. Wu et al., "Stress-dependence of the permeability and porosity of sandstone and shale from TCDP hole-A," International Journal of Rock Mechanics and Mining Sciences, vol. 47, no. 7, pp. 1141-1157, 2010.

[43] S. Ghabezloo, J. Sulem, and J. Saint-Marc, "Evaluation of a permeability-porosity relationship in a low-permeability creeping material using a single transient test," International Journal of Rock Mechanics and Mining Sciences, vol. 46, no. 4, pp. 761-768, 2009.

[44] Y. Shi and C. Y. Wang, "Pore pressure generation in sedimentary basins: overloading versus aquathermal," Journal of Geophysical Research: Solid Earth, vol. 91, no. B2, pp. 2153-2162, 1986.

[45] J. Ward, "Turbulent flow in porous media," Journal of the Hydraulics Division, vol. 90, pp. 1-12, 1964.

[46] E. F. Blick, "Capillary-orifice model for high-speed flow through porous media," Industrial \& Engineering Chemistry Process Design and. Development, vol. 5, no. 1, pp. 90-94, 1966.

[47] R. M. Fand and R. Thinakaran, "The influence of the wall on flow through pipes packed with spheres," Journal of Fluids Engineering, vol. 112, no. 1, pp. 84-88, 1990.

[48] M. G. Sidiropoulou, K. N. Moutsopoulos, and V. A. Tsihrintzis, "Determination of Forchheimer equation coefficients $a$ and $b$," Hydrological Processes, vol. 21, no. 4, pp. 534-554, 2007.

[49] S. Ergun, "Fluid flow through packed columns," Chemical Engineering Progress, vol. 48, pp. 89-94, 1952.

[50] G. Kovacs, Developments in Water Science Seepage Hydraulics, vol. 10, Elsevier, Amsterdam, 1977.

[51] R. H. Kadlec and R. L. Knight, Treatment Wetlands, Lewis Publishers, New York, NY, USA, 1996.

[52] S. Ghabezloo, J. Sulem, S. Guédon, and F. Martineau, "Effective stress law for the permeability of a limestone," International Journal of Rock Mechanics and Mining Sciences, vol. 46, no. 2, pp. 297-306, 2009.

[53] J. Rutqvist, Y.-S. Wu, C.-F. Tsang, and G. Bodvarsson, "A modeling approach for analysis of coupled multiphase fluid flow, heat transfer, and deformation in fractured porous rock," International Journal of Rock Mechanics and Mining Sciences, vol. 39, no. 4, pp. 429-442, 2002.

[54] J. Davies and D. Davies, "Stress-dependent permeability: characterization and modeling," in SPE Annual Technical Conference and Exhibition, Houston, TX, USA, 1999. 
[55] X.-W. Huang, P. Tang, X.-X. Miao, and Z. Q. Chen, “Testing study on seepage properties of broken sandstone," Rock and Soil Mechanics, vol. 26, p. 1385, 2005.

[56] Y.-F. Chen, M.-M. Liu, S.-H. Hu, and C. B. Zhou, "NonDarcy's law-based analytical models for data interpretation of high-pressure packer tests in fractured rocks," Engineering Geology, vol. 199, pp. 91-106, 2015.

[57] T. H. Chilton and A. P. Colburn, "II-pressure drop in packed tubes ${ }^{1}, "$ Industrial \& Engineering Chemistry, vol. 23, no. 8, pp. 913-919, 1931.

[58] K. N. Moutsopoulos, I. N. E. Papaspyros, and V. A. Tsihrintzis, "Experimental investigation of inertial flow processes in porous media," Journal of Hydrology, vol. 374, no. 3-4, pp. 242-254, 2009.

[59] H. Ma and D. W. Ruth, "The microscopic analysis of high Forchheimer number flow in porous media," Transport in Porous Media, vol. 13, no. 2, pp. 139-160, 1993.

[60] Y.-F. Chen, J.-Q. Zhou, S.-H. Hu, R. Hu, and C. B. Zhou, "Evaluation of Forchheimer equation coefficients for nonDarcy flow in deformable rough-walled fractures," Journal of Hydrology, vol. 529, pp. 993-1006, 2015.

[61] J. Douglas, P. J. Paes-Leme, and T. Giorgi, Generalized Forchheimer Flow in Porous Media, Army High Performance Computing Research Center, 1993.

[62] J. Geertsma, "Estimating the coefficient of inertial resistance in fluid flow through porous media," Society of Petroleum Engineers Journal, vol. 14, no. 5, pp. 445-450, 1974.

[63] R. P. Dias, J. A. Teixeira, M. G. Mota, and A. I. Yelshin, "Particulate binary mixtures: dependence of packing porosity on particle size ratio," Industrial \& Engineering Chemistry Research, vol. 43, no. 24, pp. 7912-7919, 2004.

[64] M. Mota, J. Teixeira, W. R. Bowen, and A. Yelshin, Binary Spherical Particle Mixed Beds : Porosity and Permeability Relationship Measurement, The Filtration Society, 2001.

[65] R. H. Perry, D. W. Green, and J. O. Maloney, Perry's Chemical Engineer's Handbook Chemical Engineer's Handbook, Mcgraw-Hill, 1984.

[66] W. C. Hession, V. O. Shanholtz, S. Mostaghimi, and T. A. Dillaha, "Uncalibrated performance of the finite element storm hydrograph model," Transactions of the ASAE, vol. 37, no. 3, pp. 777-783, 1994.

[67] T. S. Kornecki, G. J. Sabbagh, and D. E. Storm, "Evaluation of runoff, erosion, and phosphorus modeling system-simple," Journal of the American Water Resources Association, vol. 35, no. 4, pp. 807-820, 1999.

[68] A. B. Yu and N. Standish, "A study of the packing of particles with a mixture size distribution," Powder Technology, vol. 76, no. 2, pp. 113-124, 1993. 

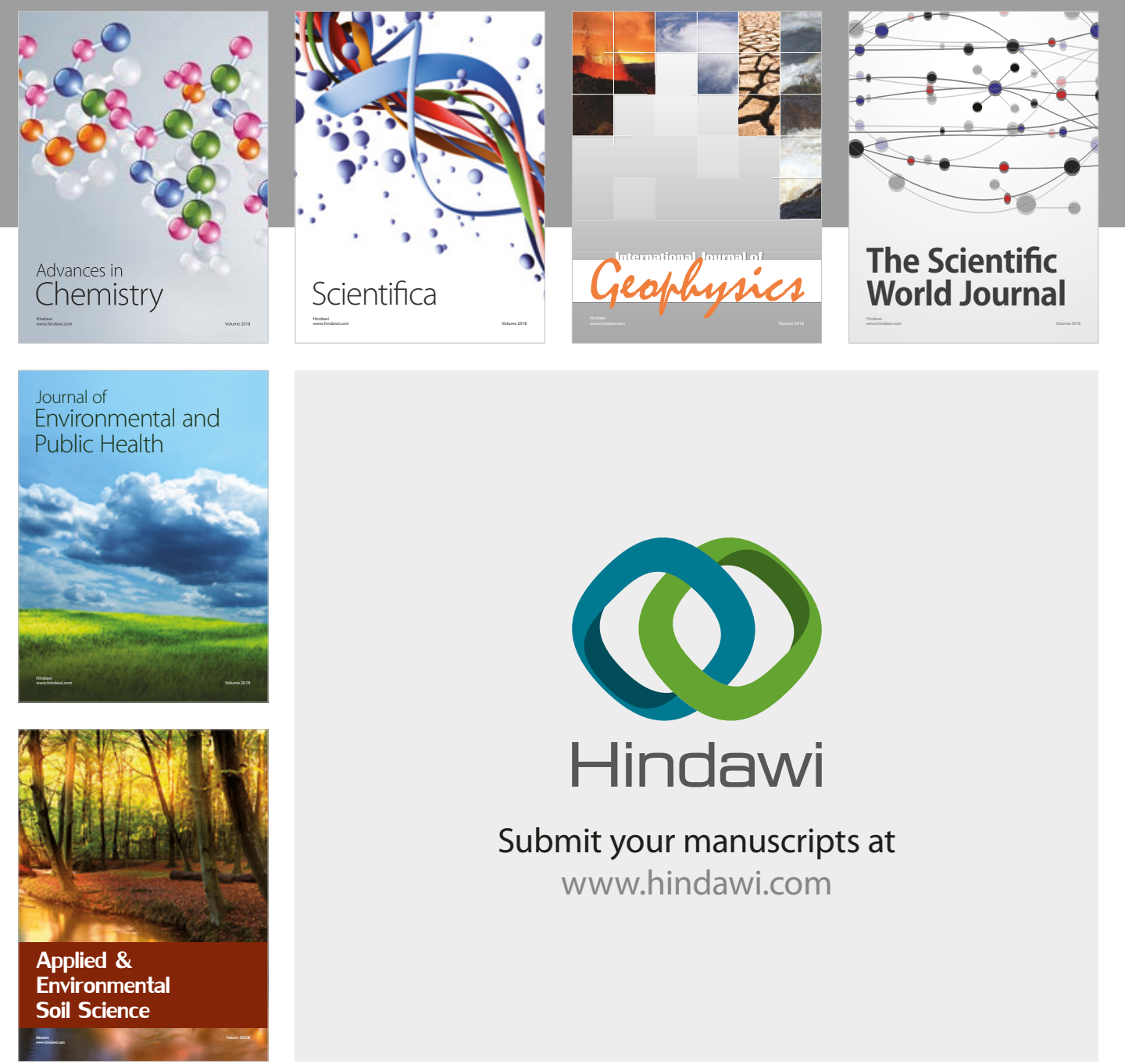

The Scientific

\section{World Journal}
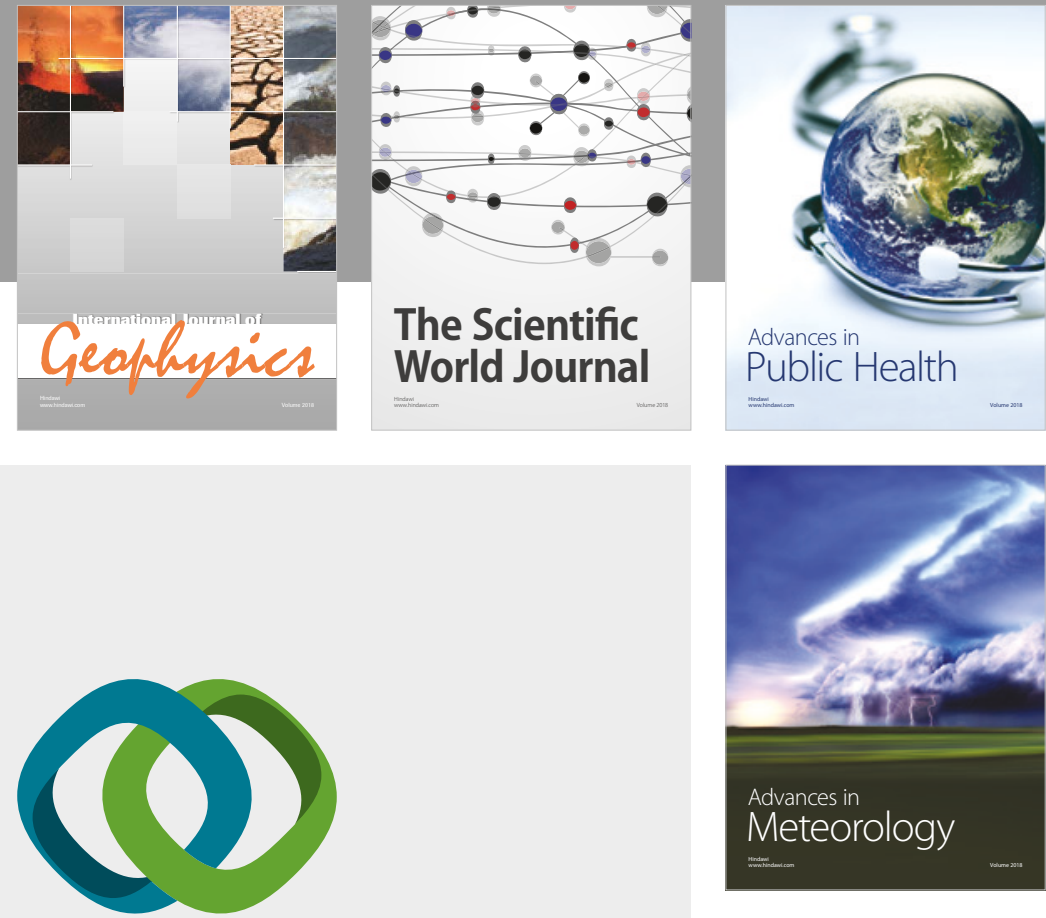

Advan

Public Health

\section{Hindawi}

Submit your manuscripts at

www.hindawi.com
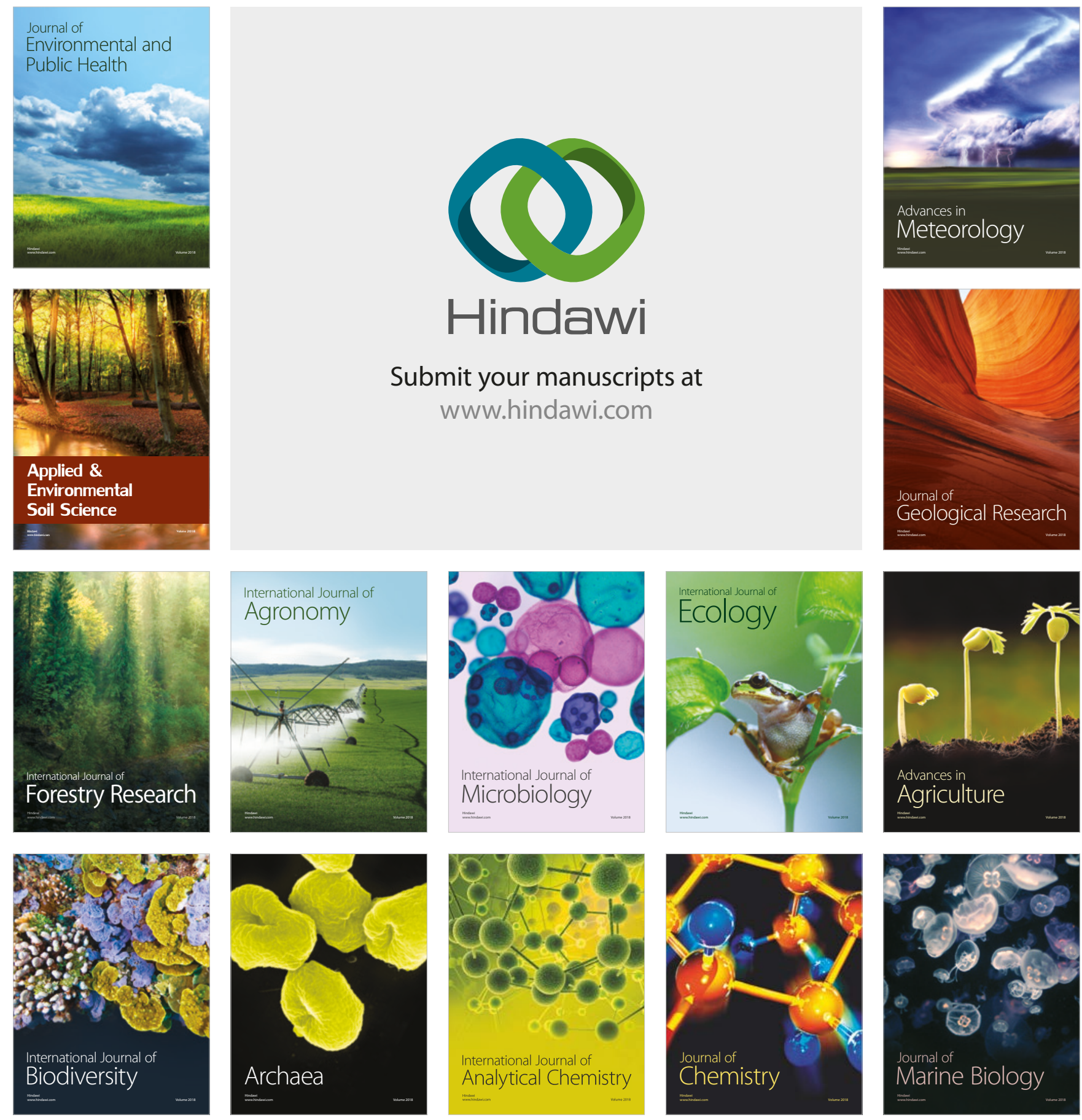